\title{
Methodology for Geometric Optimization and Sizing for Sub-Newton Monopropellant Catalyst Beds
}

\author{
Ewan Fonda-Marsland*, Graham T. Roberts ${ }^{\dagger}$, and Charles N. Ryan, ${ }^{*}$ \\ University of Southampton, Southampton, $U K$ \\ and \\ David Gibbon ${ }^{\S}$ \\ Surrey Satellite Technology Ltd, Surrey Research Park, Guildford, UK
}

\begin{abstract}
Experimental testing of a number of novel additively manufactured monopropellant micro-thrusters was conducted under atmospheric conditions, using $87.5 \%$ concentration hydrogen peroxide. The aim of this work was to select a specific catalyst bed geometry for the thruster system, and to investigate more general methodologies for monopropellant packed catalyst bed optimization. Characteristic velocity efficiencies approaching 0.98 were demonstrated, and performance improved for smaller beds with low aspect ratios, although these beds flooded at lower propellant flow rates. The onset of bed flooding was used to identify physical limits of propellant flow rate supported by the catalyst. The particular propellantcatalyst pairing limit was defined by a Damköhler number of 56, independent of the bed geometry, with thermal performance peaking for the high flow rates just before flooding occurred. It is suggested that this method is extensible to other monopropellant systems, although with further work required to confirm it is a more general effect beyond thrusters using hydrogen peroxide.
\end{abstract}

*PhD Candidate, Astronautics Group, Aeronautics and Astronautics Department; eafm1g15@soton.ac.uk.

${ }^{\dagger}$ Senior Lecturer in Propulsion (retired), Aerodynamics and Flight Mechanics Group, Aeronautics and Astronautics Department; G.T.Roberts@soton.ac.uk

* Lecturer in Astronautics, Astronautics Group, Aeronautics and Astronautics Department; C.N.Ryan@soton.ac.uk.

§Senior Propulsion Engineer; D.Gibbon@SSTL.co.uk. 


\section{Nomenclature}

Acronyms

$\begin{array}{ll}\mathrm{AM} & =\text { Additive Manufacturing } \\ \mathrm{BET} & =\text { Brunauer-Emmett-Teller } \\ \mathrm{BoL} & =\text { Beginning of Life } \\ \mathrm{CT} & =\text { Commuted Tomography } \\ \mathrm{DAQ} & =\text { Data Acquisition } \\ \text { EoL } & =\text { End of Life } \\ \mathrm{HTP} & =\text { High Test Peroxide } \\ \text { MEMS } & \text { Micro-Electro Mechanical System } \\ \text { PDS } & =\text { Propellant Delivery System } \\ \text { SLM } & =\text { Selective Laser Melting } \\ \text { SSA } & =\text { Catalyst) Specific Surface Area } \\ \text { SSTL } & =\text { Surrey Satellite Technology Ltd. (UK) } \\ \text { UoS } & =\text { University of Southampton (UK) }\end{array}$

Symbols

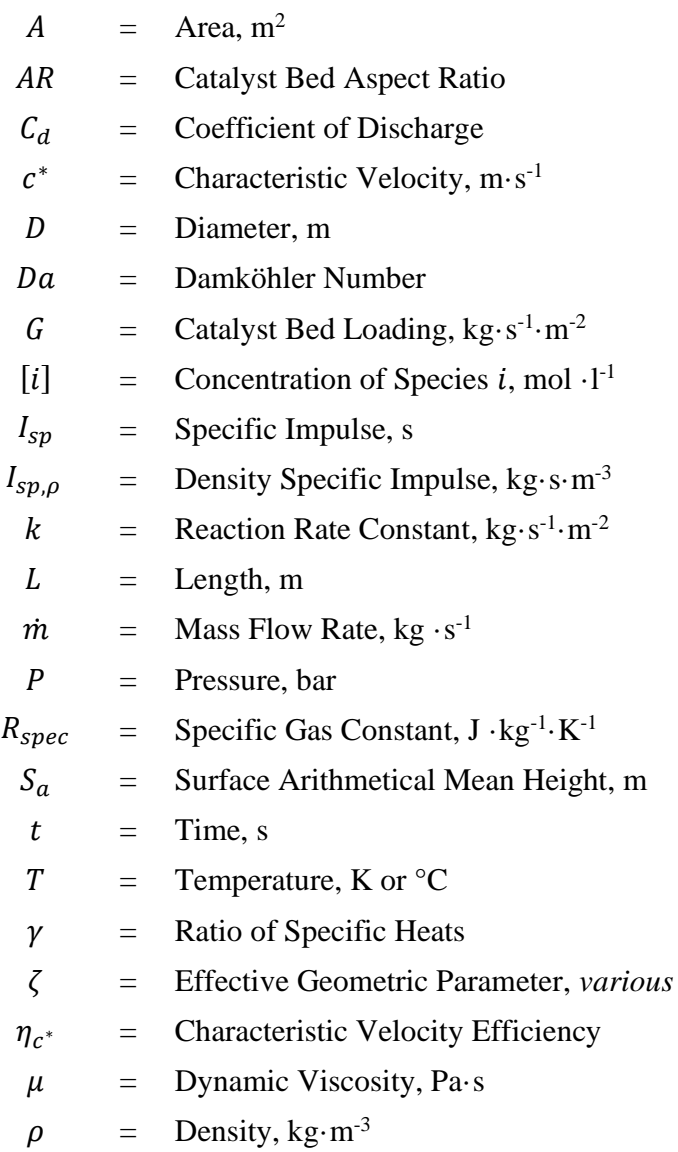




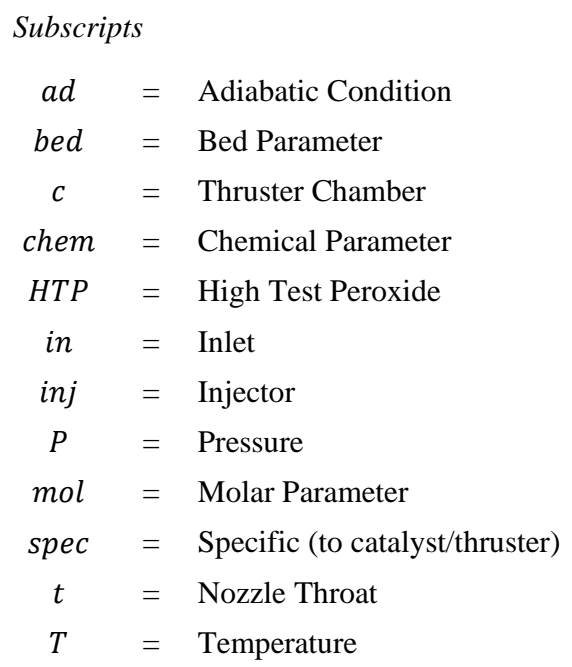

\section{I.Introduction}

The space industry is seeing small-scale satellites, with masses $100 \mathrm{~kg}$ and below, become increasingly commonplace. This growth is facilitated by component and subsystem miniaturization, removing many of the traditional limitations of these compact spacecraft. A key enabler for this greater capability is the continuing development of compact and low thrust propulsion systems. While electric propulsion is often used for these applications, these systems generally have very low thrust for a given power requirement, and also exhibit poor efficiencies for low power operation [1]. In contrast chemical monopropellant propulsion systems, especially those targeting sub-newton thrust ranges have garnered recent interest, leveraging their low system complexity, high thrust density, and low power requirements. The simplest monopropellant system may use a blowdown propellant delivery system (PDS) and thrusters consisting of a propellant injector, catalyst bed and nozzle. There are several documented modern commercial systems with nominal thrusts of $1 \mathrm{~N}$ and below, demonstrating moderate to high technological readiness levels. A selection of these is included in Table 1, listing the propellants and key performance ranges of each. 
Table 1 - A selection of current commercial small-scale chemical monopropellant thrusters, taken from publicly available online sources and marketing collateral unless otherwise stated.

\begin{tabular}{|c|c|c|c|c|c|c|c|}
\hline \multirow{2}{*}{$\begin{array}{c}\text { Company / Research } \\
\text { Group }\end{array}$} & \multirow{2}{*}{$\frac{\text { System }}{\text { MR-401 }}$} & \multicolumn{2}{|c|}{$\begin{array}{l}\text { Nominal (Range) } \\
\text { Thrust, N }\end{array}$} & \multicolumn{2}{|c|}{$\begin{array}{l}\text { Nominal (Range) } \\
\text { Specific Impulse, s }\end{array}$} & \multirow{2}{*}{$\begin{array}{l}\text { Propellant } \\
\text { Hydrazine }\end{array}$} & \multirow{2}{*}{$\begin{array}{l}\text { Flight } \\
\text { Status } \\
\text { Flown }\end{array}$} \\
\hline & & 0.09 & $(0.07-0.09)$ & & $(180-184)$ & & \\
\hline Aerojet Rocketdyne & MR-103 & 1 & $(0.19-1.13)$ & & $(202-224)$ & Hydrazine & Flown \\
\hline Aerojet Rocketdyne & GR-1 & 1 & $(0.26-1.42)$ & 235 & (max.) & AF-M315E * & Not Flown \\
\hline ArianeGroup & 1N Mono. & 1 & $(0.32-1.10)$ & 220 & $(200-223)$ & Hydrazine & Flown \\
\hline Bradford ECAPS & 100mN HPGP & 0.1 & $(0.03-0.10)$ & & $(196-209)$ & LMP-103S ${ }^{\dagger}$ & Not Flown \\
\hline Bradford ECAPS & $0.5 \mathrm{~N}$ HPGP & 0.5 & $(0.12-0.50)$ & & $(178-219)$ & LMP-103S ${ }^{\dagger}$ & Not Flown \\
\hline Bradford ECAPS & $1 \mathrm{~N} \mathrm{GP}$ & 1 & $(0.25-1.0)$ & & $(194-227)$ & LMP-103S/LT ${ }^{\dagger}$ & Not Flown \\
\hline Bradford ECAPS & 1N HPGP & 1 & $(0.25-1.0)$ & & $(204-231)$ & LMP-103S ${ }^{\dagger}$ & Flown \\
\hline Busek & BGT-X1 & 0.1 & $(0.20-0.18)$ & 214 & (max.) & AF-M315E * & Not Flown \\
\hline Busek & BGT-X5 & 0.5 & $(0.05-0.50)$ & & $(220-225)$ & AF-M315E * & Not Flown \\
\hline IHI Aerospace & 1N Mono. & 1 & $(0.29-1.13)$ & & $(208-215)$ & Hydrazine & Flown \\
\hline MOOG & MONARC-1 & 1 & & 228 & & Hydrazine & Flown \\
\hline Northrop Grumman & MRE-0.1 & 1 & & 216 & & Hydrazine & Flown \\
\hline SSTL [2] & 1N Mono. & 1 & $(0.27-1.05)$ & 151 & $(149-160)$ & HТP $87.5 \%$ & Not Flown \\
\hline Thales & 1N Mono. & 1 & $(0.36-1.45)$ & & $(205-221)$ & Hydrazine & Flown \\
\hline
\end{tabular}

All of the thrusters in Table 1 are axisymmetric designs, manufactured using conventional machining. These manufacturing processes are less suitable for lower thrust systems, due to small-scale geometry. For example a nominally $1 \mathrm{~N}$ thruster using $87.5 \%$ /wt. high test peroxide (HTP), has a $0.63 \mathrm{~mm}$ diameter nozzle throat and a $0.20 \mathrm{~mm}$ diameter orifice injector [2]. For a $0.1 \mathrm{~N}$ thruster the required nozzle throat is 0.198 mm diameter with a corresponding injector orifice of $0.063 \mathrm{~mm}$ diameter. At these scales it is challenging to create these features, and more complex geometries required to fully instrument the internal flow on experimental or breadboard thrusters is unfeasible. Most sub-newton systems developed within research institutions favor 2D planar designs, manufactured using various etching [3-5] and ceramic sintering [6-8] techniques. These methods produce planar designs on thin wafers of material, which are then stacked and bonded to create the sealed thruster cavity. Generally these techniques give much finer control over the small geometries, however they typically target thrusts several orders of magnitude lower than $1 \mathrm{~N}$. Planar designs also have issues with increased surface areas relative to the volume of the catalyst bed, resulting in poor thermal performance and increased viscous losses through the planar chamber and nozzle [3, 4, 9]. 
Delamination of the individual planar wafers is also common, exacerbated by the high temperatures and turbulent environment of a monopropellant catalyst bed. Methods to mitigate this failure mode, such as reduced chamber pressures and regenerative cooling of the walls have been demonstrated [3]. Currently there is no clear consensus on the design or manufacturing methods for planar thrusters, despite the variety of techniques investigated. However, these methods do not appear to scale well and may therefore be more suitable for smaller propulsion systems of the order of tens of $\mathrm{mN}$ and below.

Given the suitability of planar micro-electromechanical system (MEMS) -type thrusters to very low thrust ranges and the challenges in conventional fabrication of thrusters below $1 \mathrm{~N}$, there is an opportunity to investigate other manufacturing techniques for systems targeting the $0.1 \mathrm{~N}$ range. Modern metal selective laser melting (SLM) additive manufacture (AM) techniques allow the creation of complex internal geometries at the required small scales, including complex converging/diverging nozzles, support internal support structures and integrated instrumentation standpipes required for experimental performance characterization. However, AM components can have high surface roughness and poor finishes relative to conventional machining or MEMS processes. These may affect performance, especially in the transonic flow through the nozzle but, given the low flow velocities in the catalyst bed, effects upstream of the nozzle should be minimal.

For monopropellant thrusters, a full understanding of the effect of catalyst bed geometry on the thruster performance is incomplete or unpublished. Experimental work typically uses either modular thruster designs allowing for testing different configurations or a limited selection of different thruster geometries [10-12]. Some research has used computational chemical reaction modelling of the catalyst bed to investigate the effect of the design on the performance [13-15]. However, these typically rely on simplifications and have limited experimental validation. In general, both the experimental and theoretical research suggest that for a given propellant and catalyst there is an optimum bed geometry. This is dependent on the thermal and pressure losses in the bed and the completeness of the chemical decomposition reaction. However, at present there does not appear to be an accepted methodology or general investigation into identifying the key parameters for optimizing the catalyst bed.

This paper seeks to provide a comprehensive study on the effect of the principal dimensions of the catalyst bed on the performance of an AM axisymmetric micro-thruster. There is an additional goal to link performance to more fundamental mechanisms, and to identify a methodology for optimally sizing a catalyst bed that could in principle be extended to various propellant and catalyst parings. This study uses $87.5 \% / \mathrm{wt}$. HTP for the propellant 
with a commercially available catalyst using a platinum active phase supported on $300 \mu \mathrm{m}$ diameter $\gamma$-alumina spherical pellets. Usually, HTP is not a preferred monopropellant for on-orbit propulsion, given its low specific impulse with respect to hydrazine ( $230 \mathrm{~s}$ vs $178 \mathrm{~s}$ adiabatic specific impulse for hydrazine and $87.5 \%$ /wt. HTP respectively). However, for smaller volume-constrained systems such as CubeSats and secondary payloads, the higher storage density and its lower relative cost, make this system more attractive $\left(232 \mathrm{~kg} \cdot \mathrm{s} \cdot \mathrm{m}^{-3} \mathrm{vs} 245 \mathrm{~kg} \cdot \mathrm{s} \cdot \mathrm{m}^{-3}\right.$ adiabatic density specific impulse for hydrazine and $87.5 \%$ /wt. HTP respectively).

\section{II.Research Methodology}

\section{A. Baseline Thruster Design and Manufacturing}

A thruster was designed to serve as a baseline for assessing the impact of the catalyst bed geometry on the performance. The intended application is for a small propulsion system on a satellite with a target mass of $50 \mathrm{~kg}$. The design parameters of the thruster were derived by modelling the blowdown of an ideal $87.5 \% / w t$. thruster over a tank pressure range of 25 bar to 5 bar using isentropic supersonic nozzle theory. The resulting system will provide a mean thrust of $0.1 \mathrm{~N}$ over the blowdown range and a total $\Delta V$ of $100 \mathrm{~m} \cdot \mathrm{s}^{-1}$. The nozzle design was taken for the nominal $0.1 \mathrm{~N}$ thrust point, and the resulting parameters are listed in Table 2. This table includes the ideal modelled system as well as the baseline thruster design selected for manufacture.

The principal catalyst bed geometry can be defined using the catalyst bed loading $(G)$ and aspect ratio $(A R)$ :

$$
\begin{aligned}
& G=\dot{m} / A_{c} \\
& A R=L / D
\end{aligned}
$$

where the physical geometry of the bed is described by the length $(L)$ and diameter $(D)$, a cross-sectional area $\left(A_{c}\right)$ and the propellant mass flow rate $(\dot{m})$. The baseline bed was sized using data from previous studies investigating low thrust $(0.5 \mathrm{mN}$ to $1 \mathrm{~N})$ HTP systems [2-4, 8, 16-19]. Considering typical catalyst bed loadings and aspect ratios for HTP thrusters at this scale, sub-newton thrusters generally demonstrated successful decomposition with high chamber

temperatures when operated with bed loadings between $0.05 \mathrm{~kg} \cdot \mathrm{s}^{-1} \cdot \mathrm{m}^{-2}$ and $37.2 \mathrm{~kg} \cdot \mathrm{s}^{-1} \cdot \mathrm{m}^{-2}$ and aspect ratios between 0.2 and 2.0. A bed loading and aspect ratio of $10 \mathrm{~kg} \cdot \mathrm{s}^{-1} \cdot \mathrm{m}^{-2}$ and 2 respectively, were selected as a baseline for a nominal design chamber pressure of 8 bar. These values fall within the ranges from literature and are similar to larger thrusters developed at the University of Southampton (UoS) [2]. 
Table 2 - Key design and performance parameters of the baseline thruster including the numerical ideal and manufacturing design values.

\begin{tabular}{lcc}
\hline \hline Parameter & Ideal & Design \\
\hline Nominal Chamber Pressure, bar & 7.98 & 8 \\
Nominal Thrust, N & 0.1 & $(0.1)$ \\
Nozzle Throat Diameter, mm & 0.363 & 0.36 \\
Nozzle Exit Diameter, mm & 0.497 & 0.49 \\
'Nozzle Convergence Half Angle, $^{\circ}$ & N/A & 60 \\
Nozzle Divergence Half Angle, $^{\circ}$ & N/A & 15 \\
Catalyst Bed Diameter, mm $^{\text {Catalyst Bed Length, mm }}$ & 3.59 & 3.50 \\
\hline \hline
\end{tabular}

An engineering drawing of the nominal thruster design is given in Figure 1, with components and key dimensions labelled. The thrusters were manufactured from SS 316L using metal SLM on a Trumpf Truprint 1000 machine with a $15 \mu \mathrm{m}$ diameter mean powder particle size. The resolution allows for the small complex geometry, not feasible to manufacture using conventional machining, including the nozzle catalyst retainer support arches and the instrumentation standpipes. Wall thicknesses were given a lower bound of $0.30 \mathrm{~mm}$ for manufacturability. The catalyst material in the bed was retained by two punched open-cell $\mathrm{Ni}$ foam discs, nominally $1.6 \mathrm{~mm}$ thick with an approximate pore size of $300 \mu \mathrm{m}$. These were compressed to $0.6 \mathrm{~mm}$ thickness to reduce their axial pore size and to create an interference fit to better retain the $300 \mu \mathrm{m}$ diameter catalyst pellets. The catalyst bed-nozzle component was attached to the injector head by a bolted flange and sealed with a high temperature polyaramid-glass fiber gasket.

The SLM process parameters include a layer thickness of $30 \mu \mathrm{m}$, a $150 \mathrm{~W}$ beam power, a scanning speed of $675 \mathrm{~mm} \cdot \mathrm{s}^{-1}$ and a $100 \mu \mathrm{m}$ hatch spacing, giving an energy density of $74.1 \mathrm{~kJ} \cdot \mathrm{mm}^{-2}$. Each thruster was printed with the nozzle oriented towards the base plate and was given minimal post-processing on the sealing flange and nozzle exit. The resulting components had relatively high roughness compared to conventionally machined surface, particularly on the lower (with respect to the printer powder bed) outer surfaces due to removal of the required support material. 

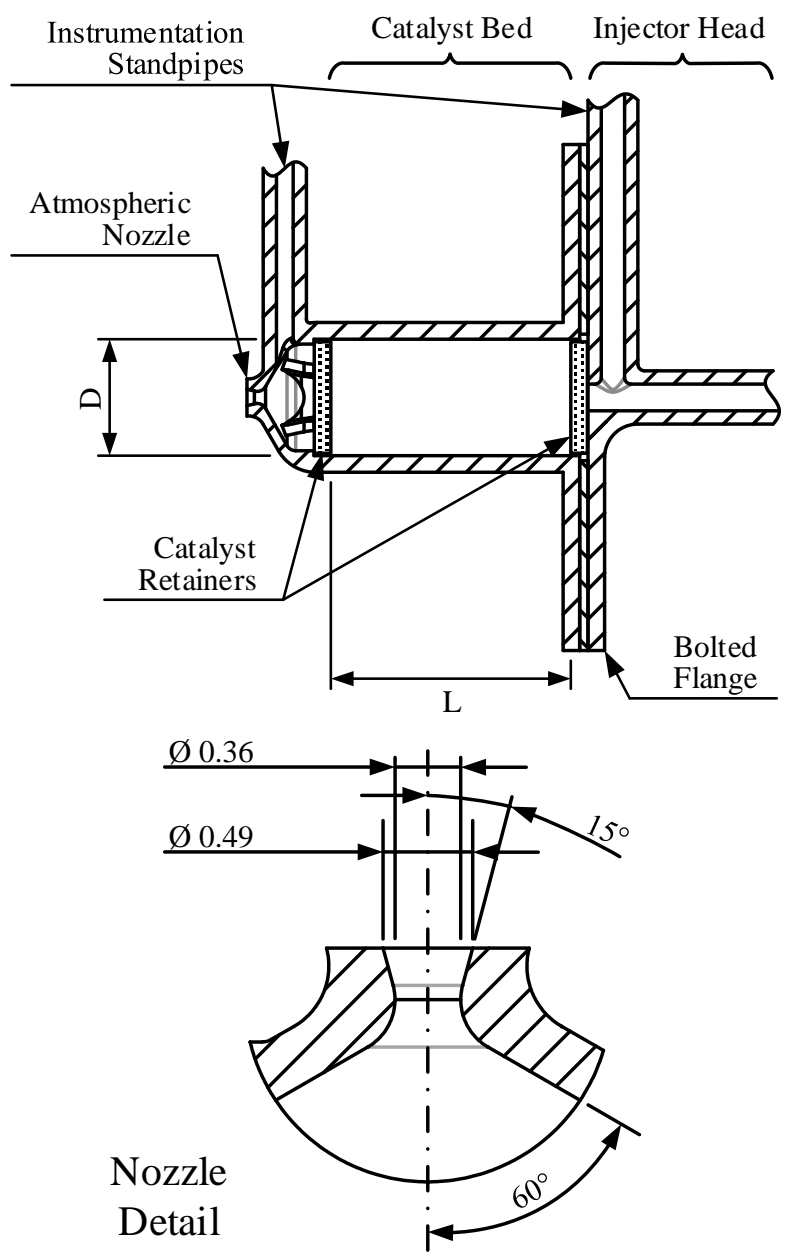

Figure 1 - Baseline thruster design and key dimensions (given in mm unless specified).

The internal surface roughness is important given the potential viscous losses. Using 3D meshed geometry generated from x-ray commuted tomography (CT) scan data of the thruster, the surface arithmetical mean height $\left(S_{a}\right)$ is estimated to be $10 \mu \mathrm{m}$ for vertical walls and $30 \mu \mathrm{m}$ for the $60^{\circ}$ convergent nozzle section. An example of the geometry is shown in the sectioned CT micrograph in Figure 2. The voxel resolution of the CT data is $21 \mu \mathrm{m}$ and the complex geometry of the thruster results in x-ray shadowing on the raw images, resulting in some uncertainty in the $S_{a}$ measurements. There are also noticeable voids in the material, located at the intersection between the wall and infill paths, in particular in the cylindrical section walls. While these will affect the material properties, the design took potential defects and porosity into account and the components were deemed satisfactory for testing.

The effect of the increased roughness is especially important for the expected high velocity flow through the nozzle. Additionally, while the roughness on the cylindrical and conical surfaces appears to be low, in the areas with 
more complex and smaller scale geometries such as the throat, there is greater surface height variability. It should be noted that there is considerable roughness on the outer surface of the nozzle apparent in Figure 2. This is a result of the AM support material but should not have any detrimental effect on the thruster performance. The internal converging surface was free from any support, hence the lower $30 \mu \mathrm{m} S_{a}$ measurement.

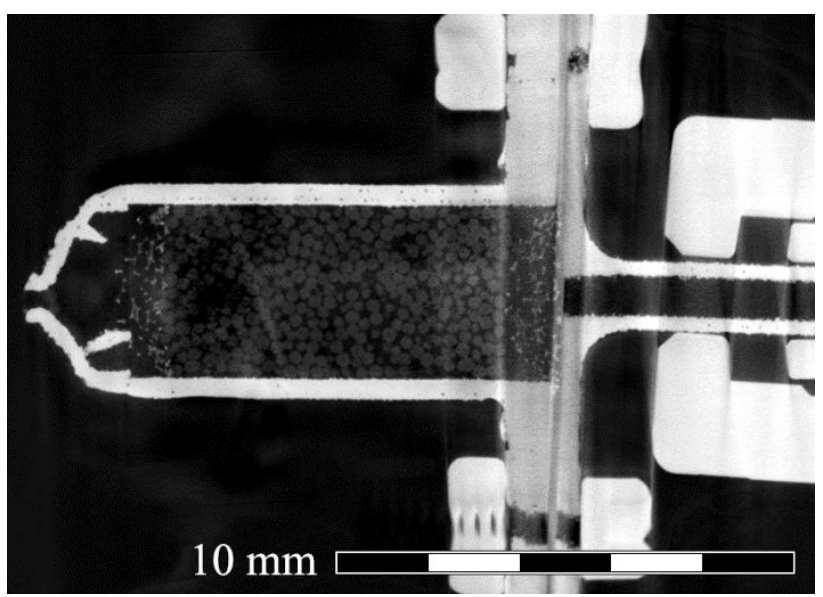

Figure 2 - A slice of CT micrograph of the baseline AM thruster, sectioned through the central axis of the bed. Absolute pixel brightness has been adjusted to better visualize the catalyst pellets; however this has also increased the brightness of the shadowing artefacts.

As described in the next section, several different thrusters were manufactured, each with a different catalyst bed size but identical nozzle design. Variations in the geometry, notably the circularity and area of the nozzle throat, were seen across the different thrusters using qualitative optical inspection. While this would be unacceptable for a flight-rated thruster without additional processing to control the geometry, the current work focuses on the catalyst bed, and relevant performance metrics should be unaffected assuming a choked nozzle condition. Given this, the flow through the catalyst bed should only depend on the mass flow rate through the nozzle throat, given by:

$$
\dot{m}=C_{d} A_{t} \frac{P_{c} \gamma}{\sqrt{\gamma T_{c} R_{\text {spec }}}} \sqrt{\left(\frac{2}{\gamma+1}\right)^{\frac{\gamma+1}{\gamma-1}}}
$$

here the flow is a function of the throat area $\left(A_{t}\right)$ and an empirical nozzle coefficient of discharge $\left(C_{d}\right)$, as well as fluid physiochemical parameters including the ratio of specific heats $(\gamma)$ and specific gas constant $\left(R_{\text {spec }}\right)$, and the chamber stagnation temperature $\left(T_{c}\right)$ and pressure $\left(P_{c}\right)$. For a well-designed macro-scale nozzle, the discharge coefficient should 
approach 1, indicating minimal losses. However for nozzles with rough surfaces and increased dominance of viscous and boundary layer effects, for example AM or micro-nozzles, it is expected to be lower [9].

The small scales and multidimensional roughness of the nozzle throat precluded direct measurement of the throat area. Each nozzle was experimentally characterized to quantify the effective throat area $\left(C_{d} A_{t}\right)$. This effective area describes the flow through the nozzle without requiring area measurements and includes the anisentropic effects that might result from the higher roughness. It is derived by measuring the chamber pressure and mass flow rate of a known fluid (dry nitrogen gas) flowing through the nozzle. Measurements over a range of pressure conditions can be used to validate the expected linear relationship. An example of a typical raw data set and characterization curve for a nozzle is given in Figure 3, with the effective throat area determined using linear regression of equation (3) to the data. The effective throat areas for the thrusters ranged between $0.752 \times 10^{-7} \mathrm{~m}^{2}$ and $1.498 \times 10^{-7} \mathrm{~m}^{2}$, with an average of $1.115 \times 10^{-7} \mathrm{~m}^{2}$. These correspond to isentropic nozzle diameters between $0.309 \mathrm{~mm}$ diameter and $0.437 \mu \mathrm{m}$ diameter, with a mean of $0.371 \mathrm{~mm}$ diameter compared to the design value of $0.36 \mathrm{~mm}$ diameter. The results indicate that the nozzles were slightly over-sized with a high manufacturing process variability. A full list of the values is included in the next section in Table 3.
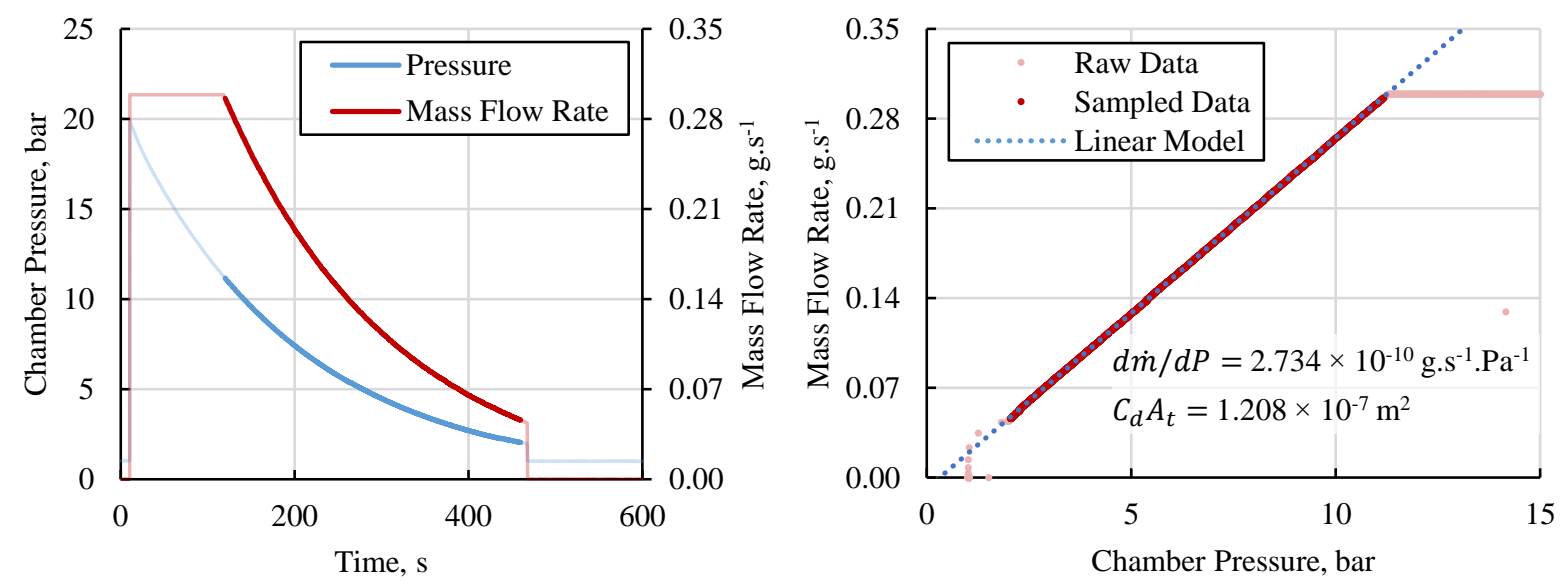

Figure 3 - Typical raw time-domain data (left) and characterization data (right) for a nozzle. The sampled dataset has been indicated.

An injector is required to control the propellant flow rate and distribution into the catalyst bed. For small monopropellant thrusters this is typically an orifice injector. This injector architecture uses liquid flow choking to create a pressure drop over the injector, decoupling the propellant feed from the unsteady regime of the catalyst bed. Careful optimization of the pressure drop is required, as larger values reduce the coupling phenomena but also decrease 
the thruster performance. For thrusts lower than $0.1 \mathrm{~N}$ the conventional orifice injectors are very small (of the order of $100 \mu \mathrm{m}$ diameter or smaller) and are more prone to manufacturing defects and blockages. An alternative design, a Poiseuille-type injector, consists of a microbore tube that can offer a comparable pressure fluctuation damping effect by using viscous effects along the length. These have a larger internal diameter and are more robust to any manufacturing variability and are typical on planar micro-thrusters $[4,20]$. The pressure drops across different injectors $\left(\Delta P_{i n j}\right)$ is related to the mass flow rate respectively by:

$$
\begin{aligned}
\Delta P_{\text {inj,orifice }} & =\dot{m}^{2} \frac{1}{2 \rho} \frac{1}{C_{d}^{2} A_{i n j}^{2}} \\
\Delta P_{\text {inj,poiseuille }} & =\dot{m} \frac{8 \pi \mu}{\rho} \frac{L_{i n j}}{C_{d} A_{i n j}^{2}}
\end{aligned}
$$

where the flow is dependent on the fluid density $(\rho)$ and dynamic viscosity $(\mu)$. Both equations include experimentally determined coefficients of discharge, calculated using the same method applied to the nozzle, using deionized water as the working fluid. Importantly, because of the linear dependence on the mass flow rate Poiseuille injectors give a constant pressure drop as a proportion of the chamber pressure, while for the orifice injector this fraction decreases as the feed (and chamber) pressure decreases. Therefore, at lower flow rates, orifice injectors can result in flow instabilities. Generally, the design fractional pressure drop is specified as a ratio of the pressure drop over the injector to the chamber pressure. Typical values for the fractional pressure drop for HTP monopropellant orifice injectors fall between $5 \% / P_{c}$ and $20 \% / P_{c}$, which is sufficient to prevent the coupled pressure instabilities [2-4]. As the fractional pressure drop of an orifice injector changes with flow rate and therefore inlet pressure, this is defined for the lowest inlet pressure at end of life (EoL) conditions. A result of this is a large fractional pressure drop at the high inlet pressures at beginning-of-life (BoL), negatively impacting performance.

In this work, all testing was conducted using Poiseuille injectors with a target nominal fractional pressure drop of $10 \% / P_{c}$, achieved using $50 \mathrm{~mm} \times 127 \mu \mathrm{m}$ diameter, cold-rolled SS 304 microbore tubes. There was some variation of the pressure drop through the experimental campaign, between $5.1 \% / P_{c}$ and $13.7 \% / P_{c}$, resulting from variations between different injector components assumed to be a result of internal roughness and other manufacturing defects. There was no noticeable pressure coupling between the propellant feed line and chamber for any of the tests reported here. 


\section{B. Catalyst Bed Selection}

To assess the impact of the principal catalyst bed geometry, a range of beds with different diameters and lengths were manufactured. These were selected using the catalyst bed loading and aspect ratio, from equations (1) and (2) respectively, and are therefore defined by the nominal mass flow rate. Table 3 lists the geometric parameters for each of the manufactured catalyst bed variants, along with the expected bed loadings as well as the empirically characterized effective throat areas for the printed nozzles for each thruster. In this table, the first block was initially manufactured to identify any interesting trends, and the second block was subsequently manufactured to investigate the trends in greater detail. The modelled bed loadings are the expected loadings based on the BoL and EoL line pressures, 5 bar and 25 bar respectively. The nozzle characterizations also include effective nozzle geometries. As noted previously there is some variability between the different nozzles. While all the nozzles choke under the test conditions, analyses of the test data must take this variability into account by using the effective throat area. A photograph of all of the catalyst bed variations is shown in Figure 4.

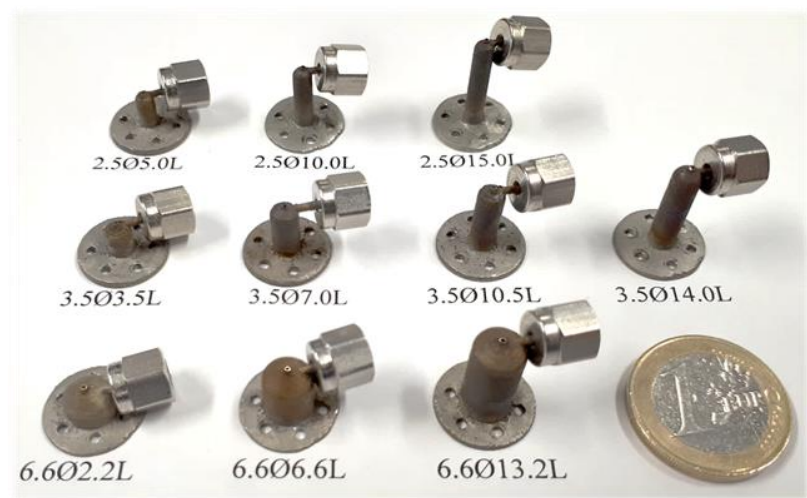

Figure 4 - A photograph all of the catalyst bed variations tested, with a 1 EUR coin for scale. 
Table 3 - Catalyst bed design parameters, along with the expected range of catalyst bed loadings and experimentally-characterized nozzle performances. The baseline thruster is highlighted in bold.

\begin{tabular}{|c|c|c|c|c|c|c|c|c|}
\hline \multirow[b]{2}{*}{$\begin{array}{l}\text { Thruster } \\
\text { Notation }\end{array}$} & \multicolumn{3}{|c|}{ Bed Geometry } & \multicolumn{3}{|c|}{ Modelled Bed Loadings, $\mathrm{kg} \cdot \mathrm{s}^{-1} \cdot \mathrm{m}^{-2}$} & \multirow{2}{*}{$\begin{array}{l}\text { Effective } \\
\text { Nozzle } \\
\text { Throat } \\
\text { Area, } \mathrm{m}^{2}\end{array}$} & \multirow[b]{2}{*}{$\begin{array}{c}\text { Effective } \\
\text { Nozzle } \\
\text { Diameter, } \mu \mathrm{m}\end{array}$} \\
\hline & $\begin{array}{l}\text { Diameter, } \\
\mathrm{mm}\end{array}$ & $\begin{array}{l}\text { Length, } \\
\text { mm }\end{array}$ & $\begin{array}{l}\text { Aspect } \\
\text { Ratio }\end{array}$ & $\begin{array}{c}\text { BoL } \\
P_{\text {in }}=25 \\
\text { bar }\end{array}$ & $\begin{array}{l}\text { Nominal } \\
P_{c}=8.0 \\
\text { bar }\end{array}$ & $\begin{array}{c}\text { EoL } \\
P_{\text {in }}=5 \\
\text { bar }\end{array}$ & & \\
\hline $2.5 \varnothing 5.0 \mathrm{~L}$ & 2.5 & 5.0 & 2 & 58.9 & 19.6 & 11.8 & $1.155 \times 10^{-7}$ & 383.5 \\
\hline $3.5 \varnothing 3.5 \mathrm{~L}$ & 3.5 & 3.5 & 1 & 30.0 & 10.0 & 6.01 & $1.498 \times 10^{-7}$ & 436.7 \\
\hline 3.5Ø7.0L & 3.5 & 7.0 & 2 & 30.0 & 10.0 & 6.01 & $1.208 \times 10^{-7}$ & 392.2 \\
\hline $3.5 \varnothing 10.5 \mathrm{~L}$ & 3.5 & 10.5 & 3 & 30.0 & 10.0 & 6.01 & $1.038 \times 10^{-7}$ & 363.5 \\
\hline $6.6 \varnothing 13.2 \mathrm{~L}$ & 6.6 & 13.2 & 2 & 8.45 & 2.82 & 1.69 & $0.952 \times 10^{-7}$ & 348.2 \\
\hline $2.5 \varnothing 10.0 \mathrm{~L}$ & 2.5 & 10.0 & 4 & 58.9 & 19.6 & 11.8 & $1.020 \times 10^{-7}$ & 360.4 \\
\hline $2.5 \varnothing 15.0 \mathrm{~L}$ & 2.5 & 15.0 & 6 & 58.9 & 19.6 & 11.8 & $1.058 \times 10^{-7}$ & 367.0 \\
\hline $3.5 \varnothing 14.0 \mathrm{~L}$ & 3.5 & 14.0 & 4 & 30.0 & 10.0 & 6.01 & $0.752 \times 10^{-7}$ & 309.4 \\
\hline $6.6 \varnothing 2.2 \mathrm{~L}$ & 6.6 & 2.2 & 0.33 & 8.45 & 2.82 & 1.69 & $1.269 \times 10^{-7}$ & 402.0 \\
\hline $6.6 \varnothing 6.6 \mathrm{~L}$ & 6.6 & 6.6 & 1 & 8.45 & 2.82 & 1.69 & $0.929 \times 10^{-7}$ & 343.9 \\
\hline
\end{tabular}

\section{Experimental Setup and Test Campaign}

All experimental work was conducted under atmospheric conditions. The PDS and thrust stand instrumentation is described in Table 4, including the measurement and uncertainty range specification. The PDS line pressure was controlled using a bang-bang controlled $\mathrm{N}_{2}$ pressurant system with a maximum operational pressure of 34 barA, allowing for testing over a range of inlet pressures expected on a flight system [2, 21]. The thrusters were tested at a number of inlet pressures, aiming to capture the performance of each bed over a representative blowdown range. The standard test inlet pressures were 5 bar, 10 bar, 15 bar, 20 bar, and 25 bar, with a nominal test duration of 60 s. Some additional tests were conducted at 30 bar to explore the upper operational envelope. The duration was chosen to allow each bed to reach steady state conditions, as indicated by both fluid temperature and pressure from the nozzle plenum standpipe. The thermocouples were visually aligned to the central axis of the thruster. Expected uncertainties in key measured and derived parameters, resulting from instrumentation, are shown in Table 5. These are calculated at the different experimental inlet pressures using the propagation of uncertainty method. Note that these estimates neglect thermal losses and any nozzle manufacturing defects.

To provide a level of repeatability, especially given the dependence of the performance on thermal effects such as preheating, prior to each test the thruster temperature was set to below $50{ }^{\circ} \mathrm{C}$. This was necessary for 
subsequent runs, where each thruster was allowed to cool from its previous firing temperature. Additionally, each catalyst bed was tested at least twice at each inlet pressure to identify the run-to-run spread.

Table 4 - PDS and thruster Data Acquisition (DAQ) and instrumentation equipment, including key measurement and uncertainty ranges.

\begin{tabular}{lcccc}
\hline \hline $\begin{array}{l}\text { Instrument / } \\
\text { Hardware }\end{array}$ & $\begin{array}{c}\text { Signal } \\
\text { Type }\end{array}$ & $\begin{array}{c}\text { Signal } \\
\text { Range }\end{array}$ & $\begin{array}{c}\text { Uncertainty } \\
{[\%]}\end{array}$ & $\begin{array}{c}\text { Data } \\
\text { Rate } \\
{[\mathrm{Hz}]}\end{array}$ \\
\hline $\begin{array}{l}\text { National Instrument } \\
\text { DAQ }\end{array}$ & N/A & N/A & N/A & 2000 \\
$\begin{array}{l}\text { Coriolis Flow Meter } \\
{\left[\mathrm{g} \cdot \mathrm{s}^{-1}\right]{ }^{* 1}}\end{array}$ & $0-2.778$ & $0.20^{\dagger 1}$ & 5 \\
$\begin{array}{l}\text { Pressure Transducer, } \\
\begin{array}{l}\text { Sputtered Film } \\
\text { Thermocouple, } \\
\text { Type-k }\end{array}\end{array}$ & {$[\mathrm{barG}]^{* 1}$} & $0-27$ & $0.25^{\dagger 2}$ & 1000 \\
\hline \hline
\end{tabular}

*1 $\quad$ Measured as voltage by NI 9205 DAQ voltage input card

*2 As measured by NI 9213 DAQ thermocouple card

$\dagger 1 \quad$ Uncertainty as $\%$ of value

$\dagger 2 \quad$ Uncertainty as \% of Full Scale

Table 5 - Estimated experimental uncertainties due to the instrumentation at each inlet pressure.

\begin{tabular}{|c|c|c|c|c|c|c|}
\hline \multirow[b]{2}{*}{ Parameter } & \multicolumn{6}{|c|}{ Uncertainty at inlet pressure, $\pm \%$} \\
\hline & 5 bar & 10 bar & 15 bar & 20 bar & 25 bar & 30 bar \\
\hline Inlet Pressure & 1.35 & 0.68 & 0.45 & 0.34 & 0.27 & 0.23 \\
\hline $\begin{array}{l}\text { Chamber } \\
\text { Pressure }\end{array}$ & 1.42 & 0.71 & 0.47 & 0.35 & 0.28 & 0.24 \\
\hline $\begin{array}{l}\text { Mass Flow } \\
\text { Rate }\end{array}$ & \multicolumn{6}{|c|}{0.20} \\
\hline $\begin{array}{l}\text { Chamber } \\
\text { Temperature }\end{array}$ & \multicolumn{6}{|c|}{0.75} \\
\hline $\begin{array}{l}\text { Characteristic } \\
\text { Velocity }(P)\end{array}$ & 1.42 & 0.71 & 0.47 & 0.35 & 0.28 & 0.24 \\
\hline $\begin{array}{l}\text { Characteristic } \\
\text { Velocity }(T)\end{array}$ & \multicolumn{6}{|c|}{0.24} \\
\hline
\end{tabular}

Some of the selected catalyst bed designs were intentionally undersized to investigate bed flooding at the high propellant flow rates. Flooding of a catalyst bed is defined here as when the boundary separating the upstream liquid/multiphase and downstream vapor phase of the reacting propellant moves beyond the end of the catalyst bed. In this case partially decomposed liquid or mixed-phase propellant will pass through the nozzle, breaking the choked 
condition and resulting in a significant decrease in thruster performance. This can be seen visually by a large white plume of steam and HTP vapor, a marked decrease in chamber pressure and temperature, and an increase in the propellant mass flow rate. This phenomenon is discussed in more detail further on.

The flooding onset conditions are considered a function of the bed geometry and mass flow rate, with higher bed loadings pushing the decomposition front downstream. Smaller and shorter catalyst beds are therefore more likely to flood and the lowest propellant mass flow rate demonstrating flooding is expected to be linked to the activity of the catalyst. Once flooding was observed, additional tests were carried out at 1 bar increments from the previous highest non-flooding line pressure to identify the onset condition more precisely.

\section{III.Results}

\section{A. Baseline Thruster Performance}

An example of typical thruster run results is given in Figure 5, showing time domain plots of pressures, mass flow rate and temperatures for a steady state inlet pressure of 15 barA using the baseline thruster. Valve actuation is measured by sharp spikes in the time differential of the inlet pressure (not pictured). The slow start-up chamber pressure transient after the valve actuation at $0 \mathrm{~s}$ is attributed to the Poiseuille injector. There is also a large spike in the mass flow rate signal at thruster initiation due to the rapid filling of the small ullage downstream of the firing valve, and the vibration due to the valve actuation respectively. Both of these effects stabilize within the first $10 \mathrm{~s}$ of firing. The system also appears stable, repeatably reaching a steady state regime within the $60 \mathrm{~s}$ test.

The main metric used for assessing the steady state performance of the catalyst bed is the characteristic velocity $\left(c^{*}\right)$. It can be calculated using two methods, each using independently measured experimental data:

$$
\begin{aligned}
c_{P}^{*}= & \frac{P_{c} C_{d} A_{t}}{\dot{m}} \\
c_{T}^{*}= & \frac{\sqrt{\gamma T_{c} R_{\text {spec }}}}{\gamma \sqrt{\left(\frac{2}{\gamma+1}\right)^{\frac{\gamma+1}{\gamma-1}}}}
\end{aligned}
$$

The first method uses the steady state pressure and mass flow rate, along with the effective nozzle throat area from the cold flow characterization, while the latter uses the steady state chamber temperature and the exhaust physiochemical parameters, derived using the NASA CEA computational code [22]. In the ideal (isentropic) case, 
both definitions are equivalent. These metrics can be normalized with respect to the ideal characteristic velocity to give a characteristic velocity efficiency $\left(\eta_{c^{*}}\right)$ which is representative of the losses inherent in the catalyst bed. The ideal characteristic velocity is calculated using equation (7) and the adiabatic chamber temperature. The steady state adiabatic chamber temperature was corrected using the measured pre-bed temperature. This is essential to account for preheating of the propellant by the thermal mass of the upstream flange and inlet which increases the resulting chamber temperature. This correction was necessary, as the steady state pre-bed temperature of the propellant was found to be dependent on the mass flow rate. Higher flow rates cool the flow at the injection plane and have a non-negligible effect on the decomposition temperature. Without this correction, the temperature-derived characteristic velocity efficiencies are often above unity, implying a higher than adiabatic thermal performance.
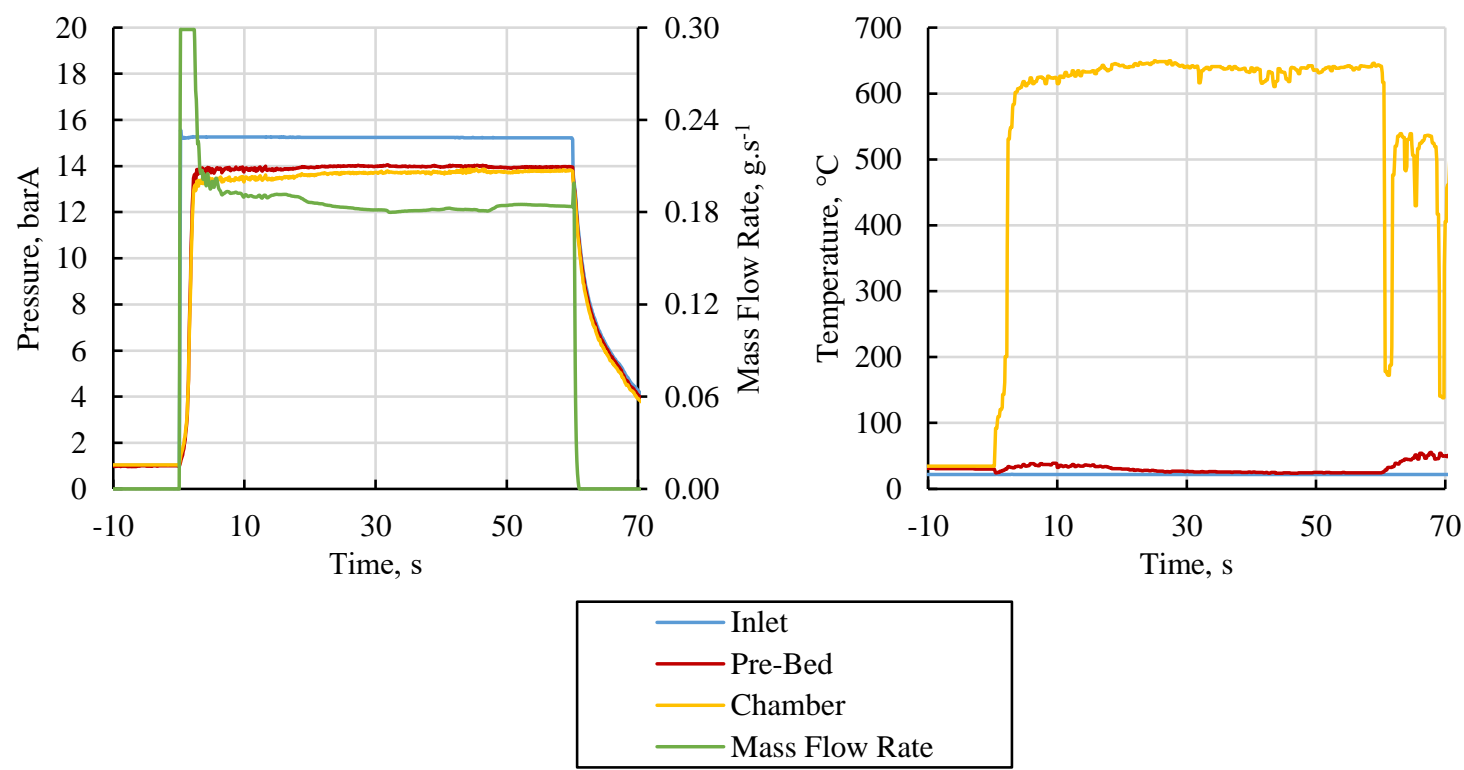

Figure 5 - An example hot-firing test showing the time-domain pressures and mass flow rate (left), and temperatures (right) for the baseline $3.5 \mathrm{~mm}$ diameter $7.0 \mathrm{~mm}$ length thruster at $P_{\text {in }}=15 \mathrm{bar}$.

The pressure and temperature-derived characteristic velocity efficiencies with respect to the steady state catalyst bed loading are shown in Figure 6. The two methods yield roughly similar results, with the bulk of the characteristic velocity efficiencies approaching $0.95-0.98$ for increasing bed loading, which are comparable to typical values for larger thrusters using this propellant $[2,23]$. However, there are some differences, with higher values typically resulting from the pressure method, in some cases above unity which is erroneous. It is currently uncertain 
why this phenomenon has occurred: the propagated uncertainty from the instrumentation hardware and any thermal drift effects $\left(< \pm 1.42 \%\right.$ and $< \pm 2 \%$ of $\eta_{c_{P}^{*}}$ respectively) are well within than the spread of the data. The values from both methods approach each other with increasing bed loadings, and there appear to be two distinct trends. It is suggested that there is a fundamental physical effect causing the observed effect at the lower bed loadings. The tests with above-unity pressure-based efficiencies all feature a high pre-bed temperature, which may indicate that there is some unknown temperature effect responsible for these anomalously high values, but further work is needed to establish the cause. This was a common trend across all of the tested catalyst beds, so for the remainder of the analysis using the characteristic velocity only the temperature method is used.

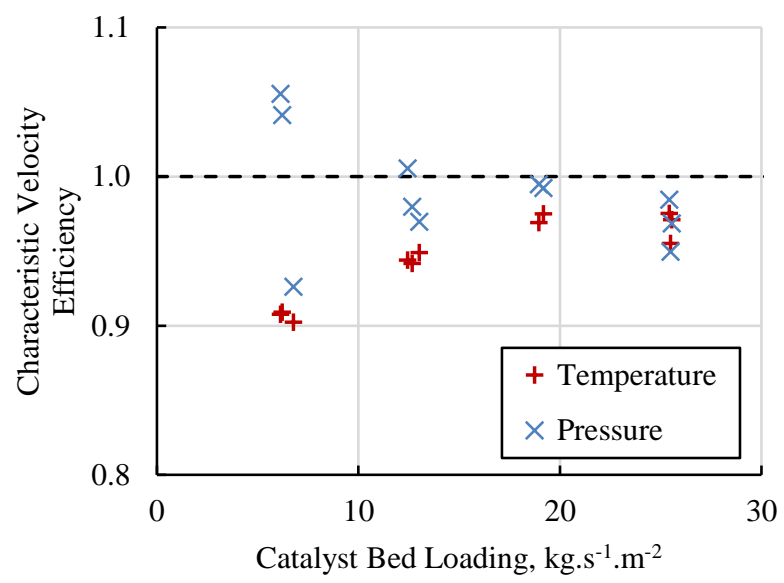

Figure 6 - Plots of the steady-state pressure and temperature-derived characteristic velocity efficiencies against the catalyst bed loading for the baseline thruster.

\section{Catalyst Bed Performance Comparison}

The value of temperature-derived characteristic velocity efficiency is expected to vary with the balance of the enthalpy flux in and out of the bed, and its direct effect on the chamber temperature at the plenum of the nozzle. Under nominal operation, the enthalpy flux into the bed is governed by the propellant mass flow rate, whereas the enthalpy flux out of the bed should be a combination of the exhaust flow rate and other thermal losses, for example

through conduction through the catalyst bed walls. Any significant deviation from unity implies that these thermal losses are significant with respect to the exhaust flow. 
The effect of the geometry of a catalyst bed can be investigated by looking at the characteristic velocity efficiency with respect to the mass flow rate (the performance of each bed compared to equivalent mass fluxes). Figure 7 contains this plot of all of the thruster tests, and it is apparent that there is little difference between the different geometries, i.e. the thermal loses resulting in the various surface areas and volumes of the beds, and any difference is qualitatively within the spread of the run-to-run variation. This was somewhat surprising as the thermal losses were expected to be significant for different sized thrusters. Across the range of propellant flow rates, the characteristic velocity efficiency varies between $0.62-0.99$. As with the baseline thruster, the enthalpy rate increases with the flow rate so the performance rises, approaching $0.95-0.99$. It is still suggested that for catalysts with an extremely large surface area above the values in this study, thermal losses will start to have a noticeable effect.

Despite the apparent insensitivity of the thermal losses for the tested bed geometries, catalyst bed loading and aspect ratio still appear to have a marked effect on the performance as they fundamentally control the amount and distribution of catalyst and catalytically active surface area in the bed. Figure 7 also shows a plot of the characteristic velocity efficiency with respect to the bed loading. Considering a pseudo-physical front of full propellant decomposition, located axially along the bed, the chamber temperature should peak when this front is aligned with the end of the end of the bed, nearest to the chamber thermocouple and the nozzle. In this case the maximum enthalpy has been extracted from the propellant and the heat loss is minimized. Away from this optimum condition, the temperature and therefore the performance should drop with either underutilization of the propellant (i.e. incomplete decomposition) or thermal losses after full decomposition the propellant. The catalyst bed loading controls the axial location of this decomposition front: it is a function of the mass flow rate and the available catalytic surface area over the bed cross-section. For a given bed geometry, increasing the loading (i.e. the mass flow rate) will move the front downstream, increasing the chamber temperature and efficiency. At some point, an optimum will be reached and as the flow rate increases further, underutilization effects are expected to take over, decreasing the performance. The extreme case of propellant underutilization will result in the bed flooding, where insufficient decomposition occurs to vaporize the propellant and liquid passes through the nozzle breaking the choking condition. 

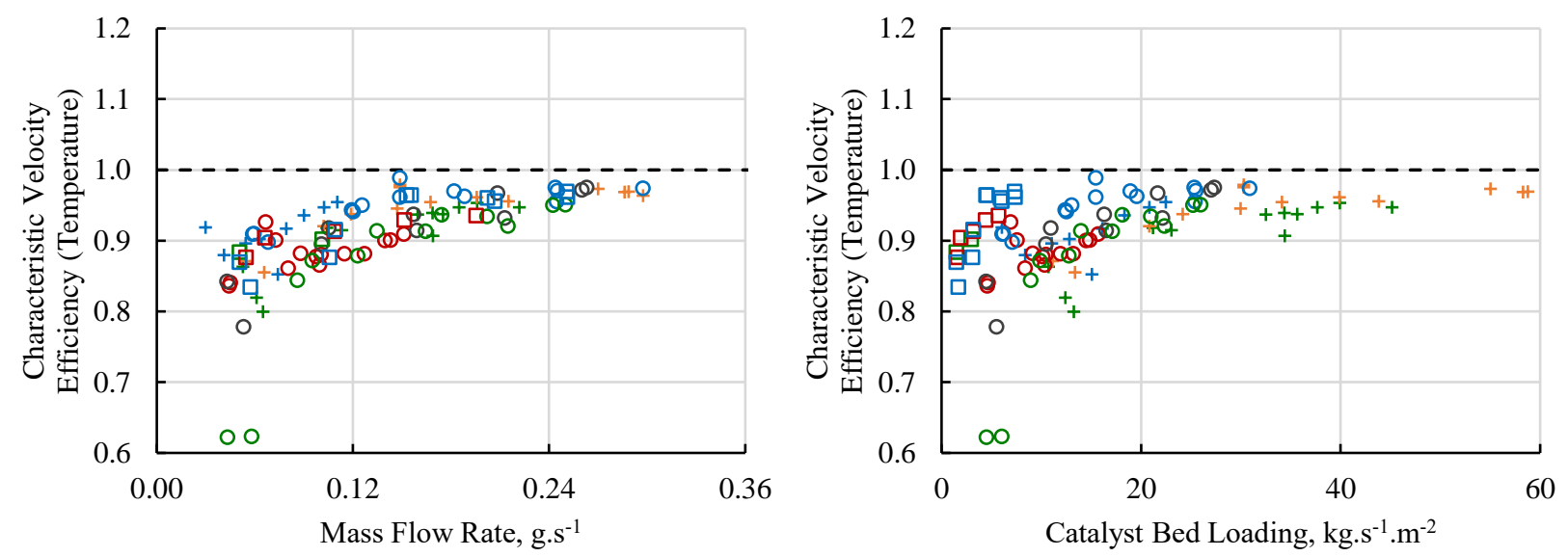

$\begin{array}{llll}+2.5 \varnothing 5.0 \mathrm{~L} & +2.5 \varnothing 10.0 \mathrm{~L} & +2.5 \varnothing 15.0 \mathrm{~L} & \\ 03.5 \varnothing 3.5 \mathrm{~L} & 03.5 \varnothing 7.0 \mathrm{~L} & 03.5 \varnothing 10.5 \mathrm{~L} & 03.5 \varnothing 14.0 \mathrm{~L} \\ \square 6.6 \varnothing 2.2 \mathrm{~L} & \square 6.6 \varnothing 6.6 \mathrm{~L} & \square 6.6 \varnothing 13.2 \mathrm{~L} & \end{array}$

Figure 7 - Characteristic velocity efficiencies for different catalyst bed loadings, calculated using chamber pressure (left) and chamber temperature (right) for the entire set of thrusters.

From Figure 7 larger cross-sectional areas appear to reach higher characteristic velocity efficiencies at lower catalyst bed loadings more consistently (e.g. $6.6 \mathrm{~mm}$ diameter data concentrated in the top right of the figure). This follows the expected behavior where the characteristic velocity efficiency converges to a maximum for higher bed loadings. An exponential model can be fitted to the data, where the coefficients can provide an insight into the maximum expected performance and rate of convergence to this upper value with respect to the bed loading. The analytic model, fitted to the temperature-derived characteristic velocity efficiency data, is:

$$
\eta_{c_{T}^{*}}=a-\frac{1}{b \exp (c G)}
$$

where $a, b$ and $c$ are regression fitting coefficients. The model implies that $a$ is the maximum $\eta_{c^{*}}$ which is achieved as $G \rightarrow \infty$, while $c$ describes the rate of convergence to $a$. The coefficient $b$ translates the curve with bed loading and can be set by the boundary constraint for when $G=0$, i.e. no mass flow rate. In this case $b=1 /\left(a-\eta_{c_{0}^{*}}\right)$, where $\eta_{c_{0}^{*}}^{*}$ is the y intercept calculated as $c_{T_{298.15 K}}^{*} / c_{T_{a d}}^{*}=0.5548$. This value is the characteristic velocity efficiency for no rise in chamber temperature. It should be noted that this intercept does not have any real physical meaning as for a non-zero mass flow rate the choking condition of a given nozzle will break. However, the coefficients $a$ and $c$ are relatively insensitive to the variation of $b$, but fixing it improves the stability of the regression algorithm. 
Coefficient $a$ can be used to assess the impact of geometry on the maximum achievable characteristic velocity efficiency. Plots with respect to both the bed cross-sectional area and aspect ratio are shown in Figure 8 . In isolation, any effect of cross-sectional area is insignificant compared to the spread in the data, agreeing with the observation that the thermal losses are insensitive to the surface area of the bed. However, the data show a clear trend of increasing performance with aspect ratio which given the previous observation is suggested to be due to the fact that a longer catalyst bed can sustain a higher mass flow rate without flooding, so can be operated with a greater enthalpy input. There is an apparent trend in this data where beds with a greater cross-sectional area need a smaller aspect ratio to achieve higher maximum characteristic velocity efficiencies, which also agrees with this hypothesis as a wider bed will also support a higher propellant flow rate before flooding.

In principle, coefficient $a$ could be used to optimize catalyst bed geometry. However, the model suggests that any increase in the enthalpy input to the system will increase the maximum characteristic velocity attainable, and implies that a bigger bed is always better given the additional mass flow rate that can be supported. For a system with a specific target thrust the propellant mass flow rate is set by the nozzle, the performance is capped by the maximum flow rate. This metric is therefore less useful for selecting bed geometry for a given target thrust.

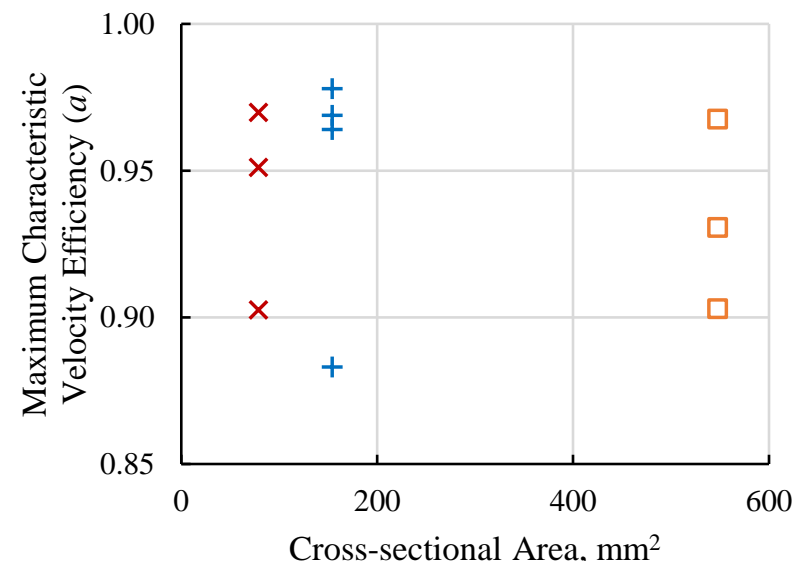

Cross-sectional Area, $\mathrm{mm}^{2}$

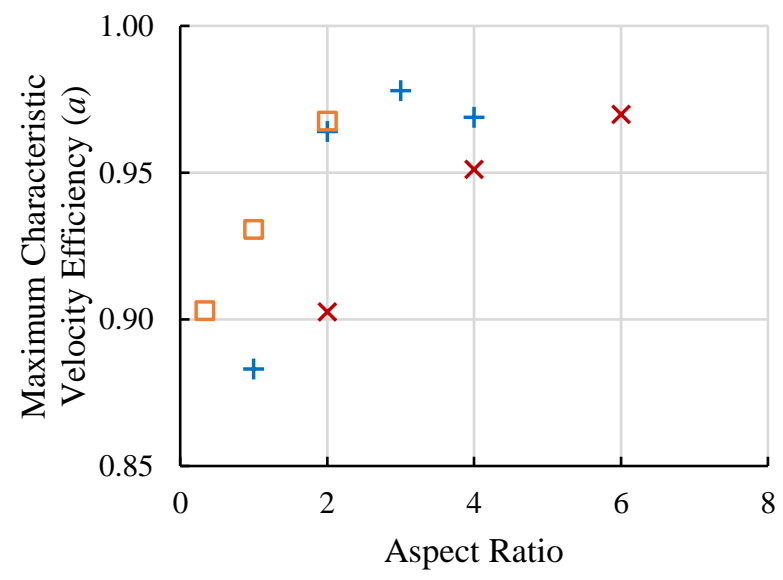

$\times 25 \# \# \#$

$+35 \# \# \#$

$\square 66 \# \# \#$

Figure 8 - Variation of the fit coefficient $a$ (maximum characteristic velocity efficiency) for the analytical model for in equation (8), with respect to the area (left) and aspect ratio (right) of the beds.

The rate of convergence to the maximum characteristic velocity efficiency is a better metric to assess a bed designed for a specific target thrust. Coefficient $c$ from the model captures this, where higher values indicate faster 
convergence at lower catalyst bed loadings. The variation of $c$ with respect to the parametric geometry is given in Figure 9. In general, this metric increases with larger cross-sectional areas and lower aspect ratios, i.e. beds that approach infinite diameters and infinitesimal lengths. This is consistent with the decomposition front model - a short and wide bed will have the front closer to the end of the catalyst bed over the range of operational mass flow rates, compared to a long and thin bed. It should be noted that this model is only valid while the length of the bed is sufficient to sustain decomposition without flooding, and conversely when the aspect ratio is either extremely large or small such that increased surface area to volume ratio results in a significant heat flux through the walls. The extent of this second requirement (very extreme area resulting in thermal loss through the walls) has not been demonstrated with the tested catalyst beds.

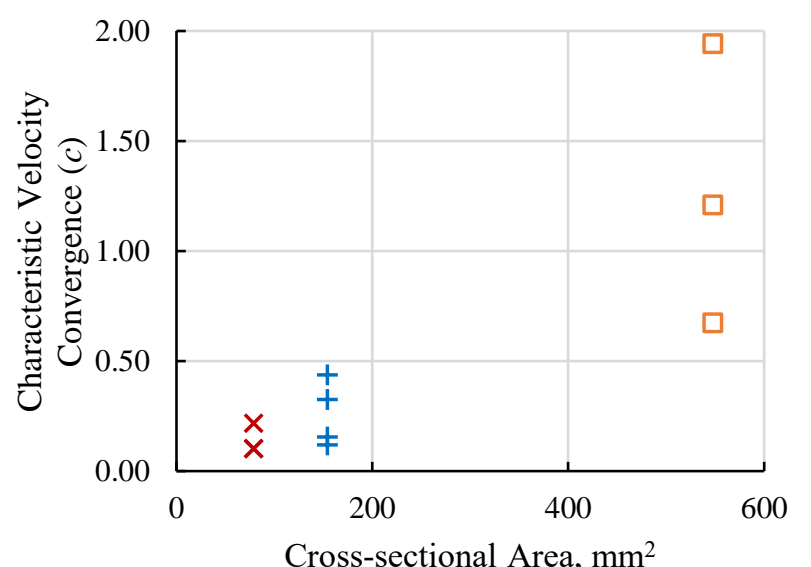

Cross-sectional Area, $\mathrm{mm}^{2}$

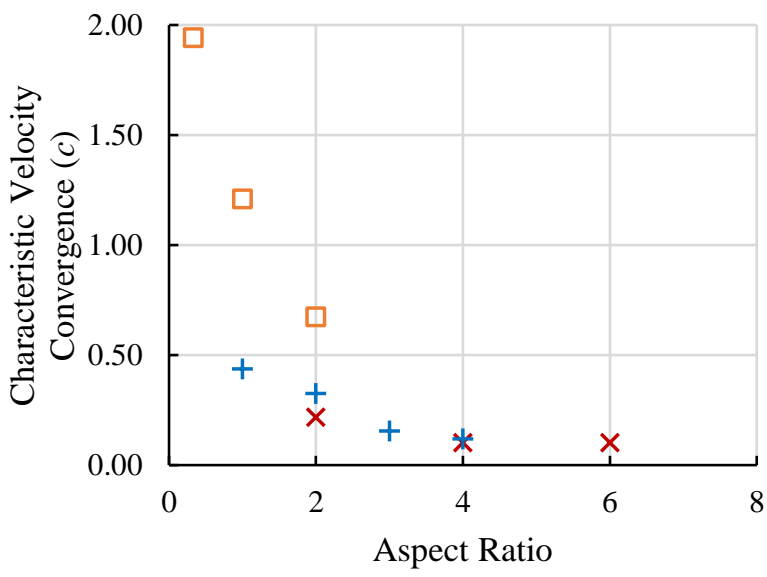

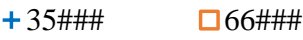

Figure 9 - Variation of the fit coefficient $c$ (convergence rate to maximum characteristic velocity efficiency) for the analytical model for in equation (8), with respect to the area (left) and aspect ratio (right) of the beds.

A larger cross-section has another benefit in reducing the catalyst bed loading. High bed loadings are associated with increased thermal and mechanical stresses on the catalyst material, decreasing its lifetime. Additionally, the higher loadings correspond to faster flow velocities in the bed which will result in greater viscous losses and a higher pressure drop between the inlet and the chamber. However, a fundamental limitation of optimizing the bed geometry by maximizing $c$ is that for a given cross-sectional area it seeks to minimize the distance between the full decomposition front and the end of the catalyst bed. Therefore as $c$ is increased, the bed will operate with the 
phase-change front closer to the end of the bed. In this case even a slight increase in the propellant flow rate will result in the sudden onset of flooding. This was directly observed with all of the low aspect ratio beds flooding at line pressures well below the maximum specified BoL pressure. The axial location of this front is related to the reaction rate of the propellant and determining the conditions for the onset of flooding is essential to optimize the bed design.

In summary, these analyses suggest that an optimum bed geometry will have a low bed loading i.e. high cross-sectional area, with the length determined by the shortest bed that can sustain the required upper propellant flow rate without flooding. This will depend on the catalytic reactivity of the bed and propellant; however the data here implies that the initial baseline geometry with a bed loading of $\sim 10 \mathrm{~kg} \cdot \mathrm{s}^{-1} \cdot \mathrm{m}^{-2}$ and an aspect ratio of $\sim 2$ was not optimal.

\section{E. Decomposition Plane Analysis}

Several of the thrusters were intentionally undersized to capture the onset of flooding. Similar to the decomposition front, this can be conceptualized as when a pseudo-physical front separating the upstream liquid/multiphase and downstream vapor/gaseous phase moves beyond the end of the catalyst bed. In this case, the liquid in the nozzle will break the choked nozzle condition causing an unrecoverable drop in chamber pressure and temperature and a rapid rise in mass flow rate. Flooding was generally observed in smaller catalyst beds. In some cases, the beds operated in a steady state mode for some time before flooding within the $60 \mathrm{~s}$ test duration, while others flooded immediately on start-up. It is suggested that this is occurs when the propellant phase-change front is very close to the end of the bed, and unsteady effects can push beyond the end. This can be seen in the example of a steady state test transitioning to a flooded condition in Figure 10. The thruster tested had a $2.5 \mathrm{~mm}$ diameter, $5.0 \mathrm{~mm}$ long catalyst bed, and was operated at an inlet pressure of 9 bar. Flooding occurred at approximately $50 \mathrm{~s}$ and the firing valve was shut after $5 \mathrm{~s}$ from the flooding onset time to limit the emission of undecomposed HTP vapor.

There is also an apparent rapid increase in the chamber temperature just prior to flooding for all datasets with a period of steady state operation. This suggests that the full decomposition front is very close to, or at the same axial position as the propellant phase-change front, and that the bulk of the propellant is decomposed in a very short timescale after the phase change. If this were not the case then underutilization effects would imply a drop in chamber temperature at higher flow rates before the flooding limit. This generally agrees with observations from literature 
using models of HTP catalytic decomposition, where there is a rapid increase in the fluid temperature and fast bulk decomposition after vaporization $[13,15]$. It is suggested that the decomposition mechanism changes once a certain temperature is reached, and thermolytic decomposition dominates. Therefore, complete decomposition is expected in all beds during stable steady-state operation with a gaseous exhaust and high chamber temperatures.

Given that the propellant decomposition rate is strongly affected by both the phase and temperature of the propellant, it is suggested that the initial decomposition rate below the boiling point (of the hydrogen peroxide $\sim 150{ }^{\circ} \mathrm{C}$ ) is the rate limiting step for the bed, i.e. liquid-phase catalytic decomposition rate. This will determine the axial location of the propellant phase-change front and therefore the flooding onset. Reaction rates can vary greatly for different HTP concentrations and catalyst active phase and microscale structure [13, 24]. The mechanism of the catalysis of hydrogen peroxide by platinum is not understood with certainty, however for higher HTP concentrations the reaction order is typically 1 , i.e. the rate is proportional to the propellant concentration. This suggests that the ratelimiting step is the first interaction between an $\mathrm{H}_{2} \mathrm{O}_{2}$ molecule and the active sites on the catalyst [24], and is therefore governed by the mass transport from the bulk fluid to the catalyst sites.

For platinum catalyst pellets the liquid phase decomposition rate constant $(k)$ for HTP was found in literature to lie between $5.39 \times 10^{-4} \mathrm{~mol} \cdot \mathrm{m}^{-2} \cdot \mathrm{s}^{-1}$ and $3.25 \times 10^{-2} \mathrm{~mol} \cdot \mathrm{m}^{-2} \cdot \mathrm{s}^{-1}$ (or $1.65 \times 10^{-5} \mathrm{~kg} \cdot \mathrm{m}^{-2} \cdot \mathrm{s}^{-1}$ and $9.96 \times 10^{-4} \mathrm{~kg} \cdot \mathrm{m}^{-2} \cdot \mathrm{s}^{-1}$ respectively for $87.5 \% / \mathrm{wt}$. HTP) calculated at $298 \mathrm{~K}$. Temperature effects are also significant, and increase the rates to $0.511 \mathrm{~mol} \cdot \mathrm{m}^{-2} \cdot \mathrm{s}^{-1}$ to $1.09 \mathrm{~mol} \cdot \mathrm{m}^{-2} \cdot \mathrm{s}^{-1}\left(1.56 \times 10^{-2} \mathrm{~kg} \cdot \mathrm{m}^{-2} \cdot \mathrm{s}^{-1}\right.$ to $\left.3.33 \times 10^{-2} \mathrm{~kg} \cdot \mathrm{m}^{-2} \cdot \mathrm{s}^{-1}\right)$ at $448 \mathrm{~K}$ (near the hydrogen peroxide boiling point) $[13,24]$. Although very wide, it is reasonable to assume that the reaction rates in the current work will fall within this range. Note that measuring the reaction rate or characterizing the specific micro-structure of this catalyst was beyond the scope of the work presented here, however it is clear that more research is required to validate these values. 

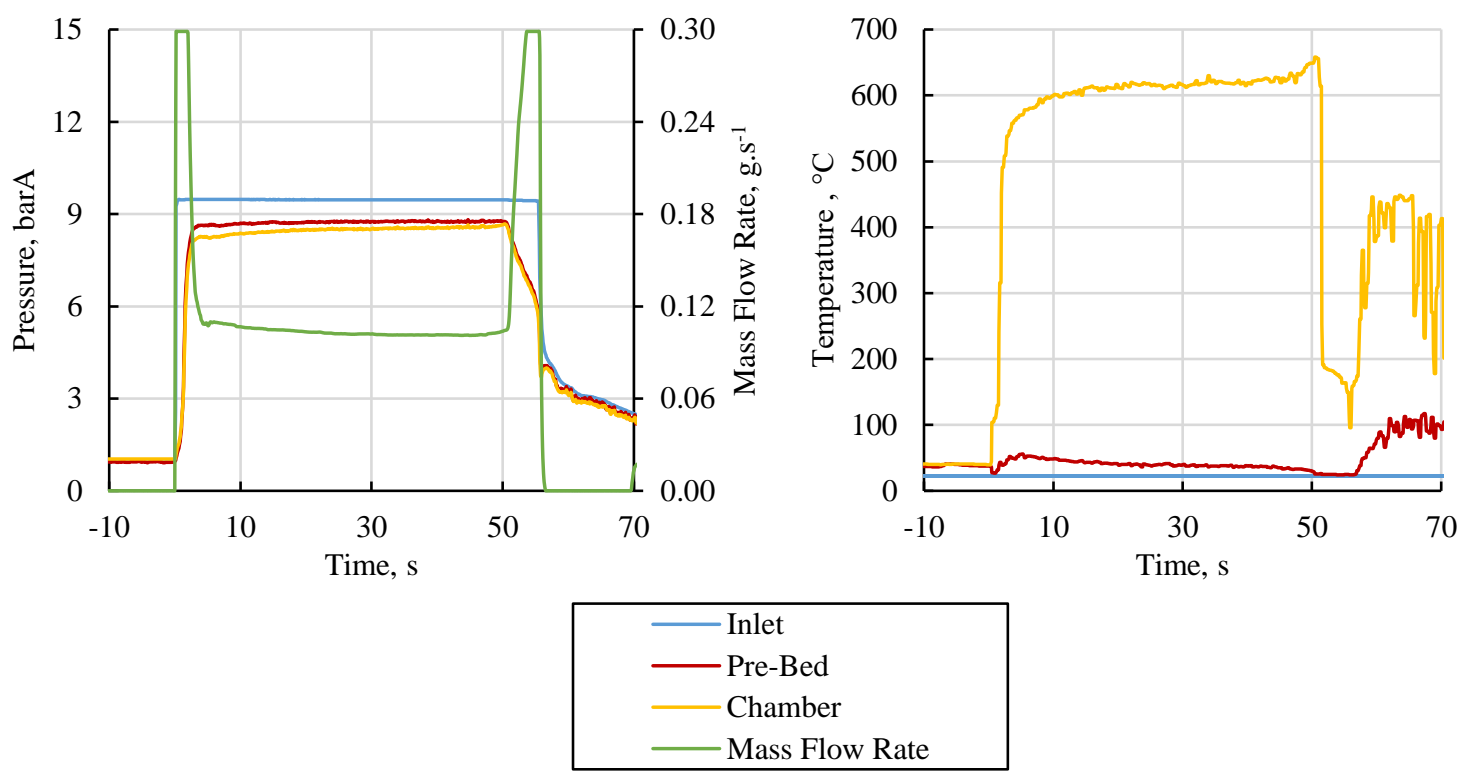

Figure 10 - An example hot-firing test showing the time-domain pressures and mass flow rate (left), and temperatures (right), highlighting the transition from steady state to flooding with an onset time of $50.4 \mathrm{~s}$. This data is from the $2.5 \mathrm{~mm}$ diameter $5.0 \mathrm{~mm}$ length thruster at $\boldsymbol{P}_{\text {in }}=9 \mathrm{bar}$.

The catalyst bed loading can be recast as a catalyst bed superficial velocity, defined as the mean velocity at which the undecomposed propellant will flow through the catalyst bed volume assuming the volume is empty of pellets. This velocity is calculated by bed loading over the fluid density, i.e. $G / \rho_{H T P}$, assuming mass continuity and a constant bed cross-sectional area. It is therefore dependent on the bed cross-sectional area and the inlet pressure (through the mass flow rate). Combining this with the bed length yields the superficial propellant residence time:

$$
t_{\text {bed }}=\frac{L \rho_{H T P}}{G}=\frac{L A_{c} \rho_{H T P}}{\dot{m}}
$$

This is an approximation of the time that the (fully liquid-phase) propellant takes to pass through the bed. Note that the actual residence time should be lower as some of the bed volume is occupied by the catalytic material but this method avoids having to measure of the void fraction. Figure 11 illustrates the superficial residence times for each catalyst bed and tested loadings. As the time decreases, the likelihood of flooding increases. For the present propellant-catalyst pairing, the onset of flooding typically occurs for residence times below $0.336 \mathrm{~s} \pm 0.028 \mathrm{~s}$, and is insensitive to the bed geometry and catalyst quantity over the range of bed loadings tested. This suggests that there is a strong correlation between the catalytic decomposition rate and the minimum residence time required to prevent 
flooding, which could provide a simple method for selecting a near optimal thruster catalyst bed with minimal experimental testing.

As mentioned, it is important to note that this threshold residence time does not take into account the volume occupied by the catalyst material. In this present work the catalyst volume fraction was estimated from the analysis of CT scans and was found to be $0.455 \pm 0.056$ across all the range of catalyst beds tested, validated with catalyst mass measurements. Hence the actual threshold residence time below which flooding is likely to occur is estimated to be less than half that based on the superficial velocity. Nevertheless, we believe the superficial residence time to be a valid and reliable indicator of the likelihood of flooding and avoids the need to measure the catalyst void fraction.

Given that a bed exhibits a maximum characteristic velocity efficiency close to flooding, and that the superficial residence time is an apparent good predictor of when a bed is close to flooding, it is proposed that this could be used to design a more optimum high-performance catalyst bed with little experimental testing. In this case, identifying the flooding onset condition for an arbitrary bed might provide insight into the parametric geometry design space that can support a given mass flow rate. This in itself could help optimize a bed with the results of the characteristic velocity efficiency study.
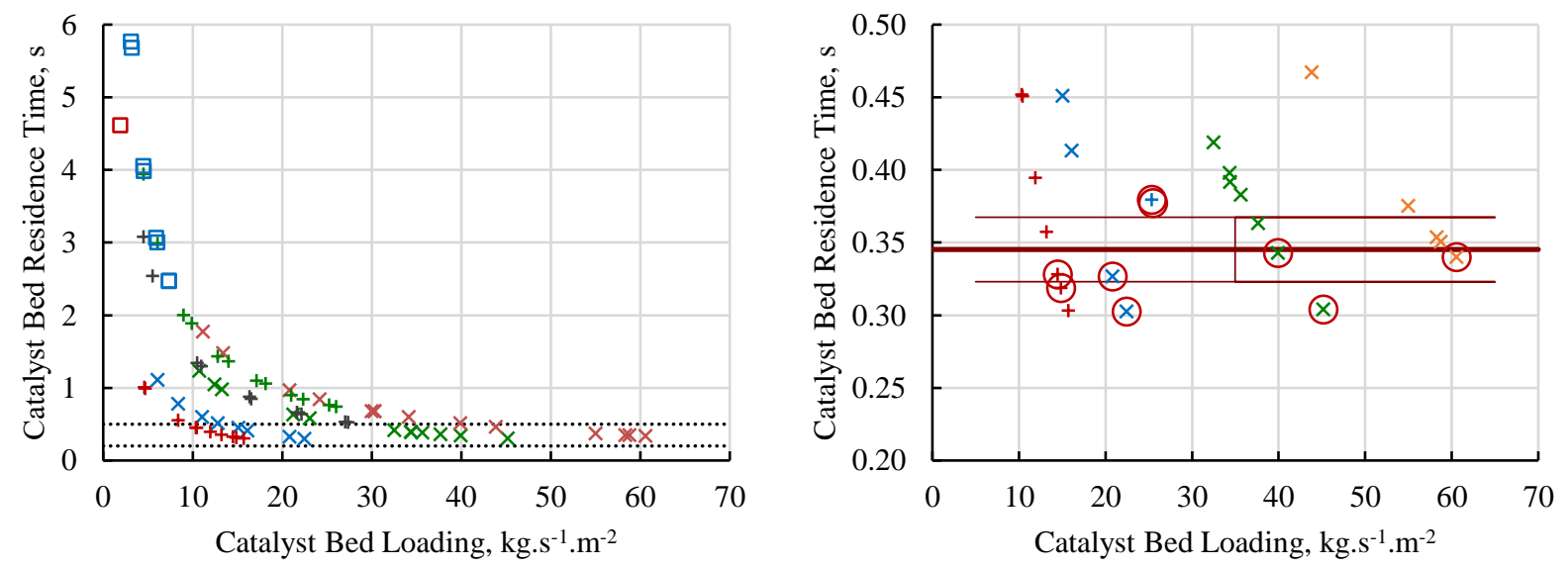

\begin{tabular}{|lll|}
\hline $2.5 \varnothing 5.0 \mathrm{~L}$ & $\times 2.5 \varnothing 10.0 \mathrm{~L}$ & $\times 2.5 \varnothing 15.0 \mathrm{~L}$ \\
$+3.5 \varnothing 3.5 \mathrm{~L}$ & $+3.5 \varnothing 7.0 \mathrm{~L}$ & $+3.5 \varnothing 10.5 \mathrm{~L}+3.5 \varnothing 14.0 \mathrm{~L}$ \\
$\square 6.6 \varnothing 2.2 \mathrm{~L}$ & $\square 6.6 \varnothing 6.6 \mathrm{~L}$ & $\square 6.6 \varnothing 13.2 \mathrm{~L}$
\end{tabular}

Figure 11 - Catalyst bed residence time with respect to catalyst bed loading. A subset (right) of the full dataset (left) for superficial residence times under $0.50 \mathrm{~s}$ highlights the flooded runs (circled). Mean flooding onset time is shown with 1 standard deviation error bar. 
The minimum residence time and therefore the upper limit mass flux of propellant sustained through the bed will be directly related to the propellant decomposition rate. This can be formalized by combining the mass flux and chemical reaction rates or representative time scales into a Damköhler number, defined using two methods:

$$
\begin{aligned}
D a_{\text {rate }} & =\frac{\text { decompostion rate }}{\text { mass transport rate }} \\
D a_{\text {timescale }} & =\frac{\text { superficial residence timescale }}{\text { decomposition timescale }}
\end{aligned}
$$

The Damköhler number can be used to give an estimation of the completeness of the decomposition reaction. Around unity, the decomposition and mass flux rates are similar, and neither process is dominant. Where $D a \gg 1$, decomposition happens faster than the reactant mass transport so the reaction will be more complete than when $D a \ll$ 1 , where reactant species pass through the bed faster than the catalyst can support. The completeness of the reaction can be defined in terms of the ratio of the reacted to unreacted species at the system outlet, in this case the exit of the catalyst bed. It is suggested that this could provide a method of approaching an optimal catalyst bed design with only knowledge of the propellant-catalyst pair reaction mechanisms and rate, and a target thrust.

Both formulations of $D a$ require the estimation of the specific chemical decomposition rate. As previously stated, this was outside of the scope of the current work however the reaction rate of the catalyst material used in this work should fall within the values from literature. Without additional data and given the assumption that the liquid phase catalysis is the rate limiting step, the following analysis is a preliminary estimation. It should be noted that the reaction rates use the steady state inlet temperature to correct the thermal effect. Given the large range of rate values, the mean rate is taken with uncertainties propagated to determine the full spread of the results.

The reaction rates must be converted to rates specific to each bed, using the catalyst specific (to each catalyst bed) surface area (SSA), i.e. $k_{\text {spec }}=k \cdot A_{\text {spec }}$. The SSA is calculated from catalyst mass and the unit catalyst surface area. Typically, the latter is measured using experimental techniques such as Brunauer-Emmett-Teller (BET) adsorption analysis. A range of $2.0 \times 10^{5} \mathrm{~m}^{2} \cdot \mathrm{kg}^{-1}$ to $2.5 \times 10^{5} \mathrm{~m}^{2} \cdot \mathrm{kg}^{-1}$ was used, as provided through discussion with the catalyst manufacturer. The SSA was estimated to lie between $10 \mathrm{~m}^{2}$ and $174 \mathrm{~m}^{2}$, resulting in specific decomposition rates from $3.00 \times 10^{-3} \mathrm{~kg} \cdot \mathrm{s}^{-1}$ to $5.36 \times 10^{-2} \mathrm{~kg} \cdot \mathrm{s}^{-1}$, both ranges depending on the bed geometry.

The rate formulation of the Damköhler number can be easily calculated assuming that propellant is fully decomposed. In this case the mass transport rate will be the mass flow rate, so: 


$$
D a_{\text {rate }}=\frac{k_{\text {spec }}}{\dot{m}}=\frac{k A_{\text {spec }}}{\dot{m}}
$$

A plot of this with respect to the catalyst bed loading is shown in Figure 12, with only values of $D a$ below 200 shown to highlight the region of interest. Note that each data point is using the mean liquid-phase catalytic decomposition rate.

The mean flooding onset has a Damköhler number of 56. A single test of the $2.5 \mathrm{~mm}$ diameter $15 \mathrm{~mm}$ length catalyst bed operated below this value in a stable steady state, although it should be noted that two other tests with the same inlet pressure (30 bar) flooded, so this may indicate a test where the phase-change front is very close to the end of the bed. The data suggests that flooding occurs when the mass transport starts to have a significant effect on the overall rate, i.e. as the order of $D a \rightarrow 1$. This also agrees with the reaction kinetics proposed for HTP-Pt catalyst from literature where the rate limiting step is the mass transport. The data have a large propagated uncertainty due to the catalyst activity and SSA so uncertainty bars are added to the mean flooding onset indicating how these affect a given result, in this case between the bounds of 3 and 164, or two orders of magnitude. The range of potential values for the onset of flooding still suggest that the decomposition is happening faster than the mass transport in all cases of steady state operation, and that flooding occurs as the two rates approach each other. This is consistent with the suggested conditions for flooding and the position of the pseudo-physical fronts inside the bed.

Although interesting, a major issue of the analysis as presented here is that the reaction kinetics are not fully understood and that many simplifications have been made to arrive at the conclusions. Further work is warranted to attempt to validate this, and to see if it is possible to link the operation of a catalyst bed to the fundamental reaction mechanisms of a propellant-catalyst pair. This could provide a more general method for designing a catalyst bed, regardless of the propellant system. 


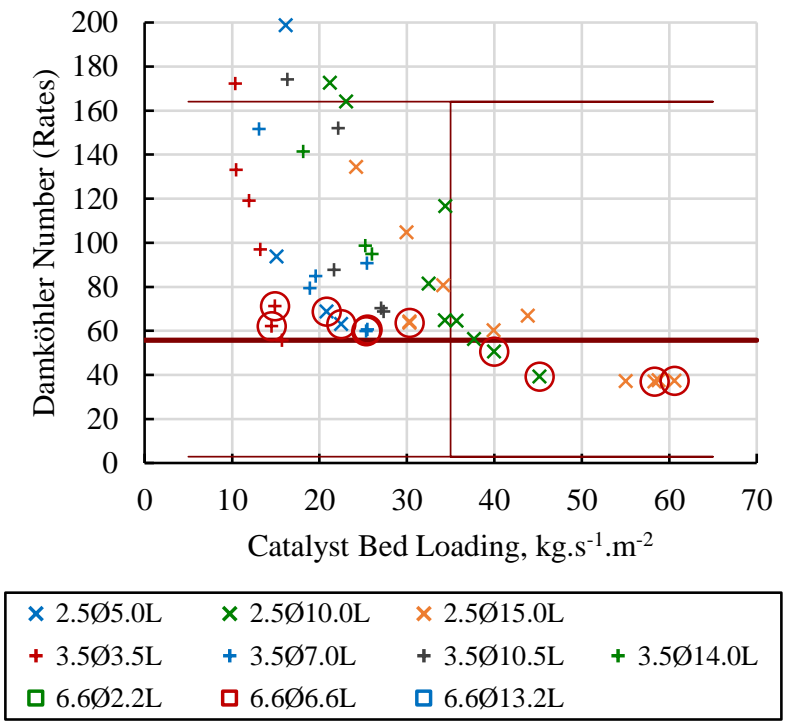

Figure 12 - Calculated Damköhler numbers from testing for $D a \leq 120$, highlighting flooded runs (circled). The mean flooding onset Damköhler number is shown with a propagated uncertainty bar, determined from the estimated parameter ranges.

\section{IV.Conclusions}

This work seeks to provide an assessment of monopropellant micro-thruster catalyst beds using $87.5 \% / w t$. HTP with a nominal $0.1 \mathrm{~N}$ thrust level. A range of parameterized catalyst bed geometries, manufactured out of SS316L using SLM AM, generally demonstrated good performance: Typical steady state chamber temperatures were above $600{ }^{\circ} \mathrm{C}$, peaking at over $650{ }^{\circ} \mathrm{C}$ for higher propellant flow rates. This was achieved in spite of minimal post processing of the printed components. However additional work is required to validate the AM technique for high performance nozzles, as the high surface roughness may result in significant losses and there is significant variability in the measured effective throat areas. Some of the catalyst beds flooded within the range inlet pressures tested, although these were deliberately undersized with high catalyst bed loadings and lower aspect ratios to investigate the onset point of bed flooding.

Characteristic velocity efficiency is used as a main metric for assessing different bed performance. Pressurederived values appear less reliable than those calculated using the temperature method, and many of the tests had values above unity. The source of this phenomenon was not identified and warrants further investigation. The 
temperature-derived values show typical values between 0.62 and 0.99 , with the bulk of the data above 0.80 . As expected, performance increases with mass flow rate due to the increased enthalpy input from the propellant. The upper values are comparable to those achieved by larger thrusters using the same propellant [2, 23].

Optimizing the size of a monopropellant thruster catalyst bed is important to maximize performance. Several criteria have been considered, including the maximum characteristic velocity efficiency achievable by a given bed, as well as the catalyst bed loadings required to approach this value. Generally, longer beds give higher potential maximum efficiencies, although this only implies that larger beds can support high propellant flow rates before the onset of flooding. The bed diameter did not appear to have a significant effect on performance, suggesting that the thermal flux through the walls did not vary greatly over the range of cross-sectional areas tested. More useful when designing a system for a specific thrust is the rate of convergence to this estimated maximum characteristic velocity efficiency with respect to bed loading. In this case, shorter and wider beds converge to a higher efficiency faster for increasing propellant flow rates, as these geometries can support the decomposition front closer to the end of the catalyst bed. One drawback of designing solely using this metric is that flooding will occur at lower propellant flow rates due to the phase-change front also being closer to the end of the bed.

Despite performance being generally good across all of the catalyst beds in their steady state regime, flooding occurred in beds with higher loading and lower aspect ratio. It has been shown that this phenomenon can be linked to the superficial propellant residence time, which provides a method of determining whether the phase-change front is likely to fall within or past the end of a specific bed for a given propellant flow rate. The propellant-catalyst pair tested in this work demonstrated a consistent flooding onset when the superficial bed residence time falls below $0.338 \mathrm{~s} \pm$ $0.028 \mathrm{~s}$. It is suggested that this is linked to the fundamental chemistry of the bed and this method could be extended to identify the flooding onset for any given propellant-catalyst system with minimal testing, aiding in parametric catalyst bed design.

The Damköhler number for the tests was estimated using liquid phase catalytic decomposition rates (the suggested limiting step) for HTP-Platinum from literature. It was found that bed flooding typically occurred when the number fell below 56. Including the propagated uncertainties due to the assumptions made about the catalyst, the uncertainly of this value falls between 3 and 164. These values, along with the trend in the data for bed loadings approaching the flooding onset, suggest that flooding occurs when the mass transport starts to become a significant effect fraction of the decomposition rate. This would agree with literature that suggests that the mass transport is the 
rate limiting step of the HTP-Pt decomposition reaction. However this work is speculative given large uncertainties in the reaction rate, and as such a significant body of further work is essential both to validate the presented results and to compare this data to other propellant and catalyst systems.

\section{V.Acknowledgements}

The authors wish to acknowledge the continued support of CTI - ALSYS Group, France for the provision of catalytic materials and associated data for use in this project.

The authors also want to thank Surrey Satellite Technology Ltd. for enabling this research through their financial support of E. Fonda-Marsland's PhD program.

Finally, the authors wish to acknowledge the UK Space Agency for their funding contributions as part of the National Space Technology Program-2 Fast Track Scheme which was used to develop the laboratory and testing facilities at the University of Southampton.

\section{VI.References}

[1] Lev, D., Myers, R. M., Lemmer, K. M., Kolbeck, J., Koizumi, H., and Polzin, K. "The Technological and Commercial Expansion of Electric Propulsion," Acta Astronautica, Vol. 159, 2019, pp. 213-227.

https://doi.org/10.1016/j.actaastro.2019.03.058

[2] Ryan, C. N., Fonda-Marsland, E., Roberts, G. T., Lear, A., Fletcher, E., Giles, L., Palmer, M. J., and Gibbon, D. "Experimental Validation of a 1-Newton Hydrogen Peroxide Thruster," Journal of Propulsion and Power, 2019, pp. 1-9. https://doi.org/10.2514/1.b37418

[3] Huh, J., and Kwon, S. "Microcooling Channel Effect on a Monopropellant Microelectromechanical System Thruster Performance," Journal of Propulsion and Power, Vol. 33, No. 6, 2017, pp. 1591-1595.

https://doi.org/10.2514/1.B36393

[4] Hitt, D. L., Zakrzwski, C. M., and Thomas, M. A. "MEMS-Based Satellite Micropropulsion via Catalyzed Hydrogen Peroxide Decomposition," Smart Materials \& Structures, Vol. 10, No. 6, 2001, pp. 1163-1175.

https://doi.org/10.1088/0964-1726/10/6/305 
[5] Yuan, T., Li, A., Huang, B., Chen, Y. T., and Chen, C. "Design, Fabrication, and Test of a Microelectromechanical-SystemBased Millinewton-Level Hydrazine Thruster," Journal of Propulsion and Power, Vol. 27, No. 2, 2011, pp. 509-512. $\underline{\text { https://doi.org/10.2514/1.50055 }}$

[6] Cheah, K. H., and Low, K. S. "Fabrication and Performance Evaluation of a High Temperature Co-Fired Ceramic Vaporizing Liquid Microthruster," Journal of Micromechanics and Microengineering, Vol. 25, No. 1, 2015, p. 015013. https://doi.org/10.1088/0960-1317/25/1/015013

[7] Cheah, K. H., Khiew, P. S., and Chin, J. K. "Fabrication of a Zirconia MEMS-Based Microthruster by Gel Casting on PDMS Soft Molds," Journal of Micromechanics and Microengineering, Vol. 22, No. 9, 2012, p. 095013.

https://doi.org/10.1088/0960-1317/22/9/095013

[8] Khaji, Z., Klintberg, L., Barbade, D., Palmer, K., and Thornell, G. "Endurance and Failure of an Alumina-Based Monopropellant Microthruster with Integrated Heater, Catalytic Bed and Temperature Sensors," Journal of Micromechanics and Microengineering, Vol. 27, No. 5, 2017, p. 055011.

https://doi.org/10.1088/1361-6439/aa6550

[9] Louisos, W. F., Alexeenko, A. A., Hitt, D. L., and Zilic, A. "Design Considerations for Supersonic Micronozzles," International Journal of Manufacturing Research, Vol. 3, No. 1, 2008, p. 80.

https://doi.org/10.1504/ijmr.2008.016453

[10] Maia, F. F., Gouvea, L. H., Pereira, L. G. F., Vieira, R., and Costa, F. D. S. "Development and Optimization of a Catalytic Thruster for Hydrogen Peroxide Decomposition," Journal of Aerospace Technology and Management, Vol. 6, No. 1, 2014, pp. 61-67.

https://doi.org/10.5028/jatm.v6i1.286

[11] An, S., and Kwon, S. "Scaling and Evaluation of Pt/A12O3 Catalytic Reactor for Hydrogen Peroxide Monopropellant Thruster," Journal of Propulsion and Power, Vol. 25, No. 5, 2009, pp. 1041-1045.

https://doi.org/10.2514/1.40822

[12] Jung, S., Choi, S., and Kwon, S. "Design Optimization of Green Monopropellant Thruster Catalyst Beds Using Catalytic Decomposition Modeling," 53rd AIAA/SAE/ASEE Joint Propulsion Conference, AIAA 2017-4924, AIAA, Atlanta, GA, USA, 2017, pp. 1-10.

https://doi.org/10.2514/6.2017-4924

[13] Koopmans, R. J., Shrimpton, J. S., Roberts, G. T., and Musker, A. J. "A One-Dimensional Multicomponent Two-Fluid Model of a Reacting Packed Bed Including Mass, Momentum and Energy Interphase Transfer," International Journal of Multiphase Flow, Vol. 57, 2013, pp. 10-28.

https://doi.org/10.1016/j.ijmultiphaseflow.2013.06.005 
[14] Pasini, A., Torre, L., Romeo, L., Cervone, A., and d'Agostino, L. "Reduced-Order Model for H2O2 Catalytic Reactor Performance Analysis," Journal of Propulsion and Power, Vol. 26, No. 3, 2010, pp. 446-453.

https://doi.org/10.2514/1.44355

[15] Zhou, X., and Hitt, D. L. "One-Dimensional Modeling of Catalyzed H2O2 Decomposition in Microchannel Flows," 33rd AIAA Fluid Dynamics Conference and Exhibit, AIAA 2003-3584, Orlando, FL, USA, 2003, pp. 1-11.

https://doi.org/10.2514/6.2003-3584

[16] Kuan, C. K., Chen, G. B., and Chao, Y. C. "Development and Ground Tests of a 100-Millinewton Hydrogen Peroxide Monopropellant Microthruster," Journal of Propulsion and Power, Vol. 23, No. 6, 2007, pp. 1313-1320.

https://doi.org/10.2514/1.30440

[17] Cen, J. W., and Xu, J. L. "Performance evaluation and flow visualization of a MEMS based vaporizing liquid micro-thruster," Acta Astronautica, Vol. 67, No. 3-4, 2010, pp. 468-482.

https://doi.org/10.1016/j.actaastro.2010.04.009

[18] Lee, J., Su-Kyum, K., Kwon, S., and Myoung-Jong, Y. "Fabrication of Catalyst-Insertion-Type Microelectromechanical Systems Monopropellant Thruster," Journal of Propulsion and Power, Vol. 28, No. 2, 2012, pp. 396-404.

https://doi.org/10.2514/1.B34287

[19] Huh, J., and Kwon, S. "Design, Fabrication and Thrust Measurement of a Micro Liquid Monopropellant Thruster," Journal of Micromechanics and Microengineering, Vol. 24, No. 10, 2014, p. 104001.

https://doi.org/10.1088/0960-1317/24/10/104001

[20] Fonda-Marsland, E., Roberts, G. T., Gibbon, D., and Ryan, C. N. "An Investigation into Injector Architecture for Sub-Newton Monopropellant Propulsion," 8th European Conference for Aeronautics and Space Sciences, PP. 08-529, Carte Blanche, Madrid, Spain, 2019, pp. 1-15.

[21] Fonda-Marsland, E., Roberts, G. T., Gibbon, D., and Ryan, C. N. "Development of a Low-Cost 0.1N High Test Peroxide Thruster Using Additive Manufacturing," AIAA Propulsion and Energy 2019 Forum, AIAA 2019-4227, AIAA, Indianapolis, IN, USA, 2019, pp. 1-17.

https://doi.org/10.2514/6.2019-4227

[22] McBride, B. J., and Gordon, S. "Computer Program for Calculation of Complex Chemical Equilibrium Compositions and Applications II. User's Manual and Program," Glenn Research Center, NASA RP-1331-P2, 1996.

[23] Essa, K., Hassanin, H., Attallah, M. M., Adkins, N. J., Musker, A. J., Roberts, G. T., Tenev, N., and Smith, M. "Development and Testing of an Additively Manufactured Monolithic Catalyst Bed for HTP Thruster Applications," Applied Catalysis AGeneral, Vol. 542, 2017, pp. 125-135.

https://doi.org/10.1016/j.apcata.2017.05.019 
[24] Serra-Maia, R., Bellier, M., Chastka, S., Tranhuu, K., Subowo, A., Rimstidt, J. D., Usov, P. M., Morris, A. J., and Michel, F. M. "Mechanism and Kinetics of Hydrogen Peroxide Decomposition on Platinum Nanocatalysts," ACS Appl Mater Interfaces, Vol. 10, No. 25, 2018, pp. 21224-21234.

https://doi.org/10.1021/acsami.8b02345 